\title{
Responses of Pigeon Vestibulocerebellar Neurons to Optokinetic Stimulation. I. Functional Organization of Neurons Discriminating Between Translational and Rotational Visual Flow
}

\author{
DOUGLAS R. WYLIE, TARUN KRIPALANI, AND BARRIE J. FROST \\ Department of Psychology, Queen's University, Kingston, Ontario K7L 3N6, Canada
}

\section{SUMMARY AND CONCLUSIONS}

1. Extracellular recordings were made from 235 ncurons in the vestibulocerebellum ( $\mathrm{VbC})$, including the flocculus (lateral $\mathrm{VbC}$ ), nodulus (folium $\mathrm{X}$ ), and ventral uvula (ventral folium $\mathrm{IXc}, \mathrm{d}$ ), of the anesthetized pigeon, in response to an optokinetic stimulus.

2. The optokinetic stimuli consisted of two black and white random-dot patterns that were back-projected onto two large tangent screens. The screens were oriented parallel to each other and placed on either side of the bird's head. The resultant stimulus covered the central $100^{\circ} \times 100^{\circ}$ of each hemifield. The directional tuning characteristics of each unit were assessed by moving the largefield stimulus in 12 different directions, $30^{\circ}$ apart. The directional tuning curves were performed monocularly or binocularly. The binocular directional tuning curves were performed with the direction of motion the same in both eyes (in-phase; e.g., ipsi = upward, contra = upward ) or with the direction of motion opposite in either eye (antiphase; e.g., ipsi = upward, contra = downward).

3. Mossy fiber units $(n=17)$ found throughout folia IXa,b and IXc, $\mathrm{d}$ had monocular receptive fields and exhibited direction selectivity in response to stimulation of either the ipsilateral $(n=12)$ or contralateral $(n=5)$ eye. None had binocular receptive fields.

4. The complex spike (CS) activity of 218 Purkinje cells in folia IXc, $\mathrm{d}$ and $\mathrm{X}$ exhibited direction selectivity in response to the largefield visual stimulus moving in one or both visual fields. Ninetyone percent of the cells had binocular receptive fields that could be classified into four groups: descent neurons $(n=112)$ preferred upward motion in both eyes; ascent neurons $(n=14)$ preferred downward motion in both eyes; roll neurons $(n-33)$ preferred upward and downward motion in the ipsilateral and contralateral eyes, respectively; and yaw neurons $(n=40)$ preferred forward and backward motion in the ipsilateral and contralateral eyes, respectively. Within all groups, most neurons (70\%) showed an ipsilateral dominance.

5. For most binocular neurons ( $91 \%)$, the maximum depth of modulation occurred with simultaneous stimulation of both eyes, compared with monocular stimulation of the dominant eye alone. For the translation neurons (descent and ascent), binocular inphase stimulation produced the maximum depth of modulation, whereas for the rotation neurons (roll and yaw), binocular antiphase stimulation produced the maximum depth of modulation.

6. There was a clear functional segregation of the translation and rotation neurons. Descent and ascent neurons were found in the medial VbC (ventral uvula and nodulus), whereas roll and yaw neurons were found in the lateral $\mathrm{VbC}$ (flocculus).

INTR ODUCTION

Self-motion of an animal through an environment containing numerous stationary visual objects results in "flow- ficlds" or "wholcficld visual motion" across the retina in the opposite direction (Gibson 1966). The accessory optic system (AOS) is a separate visual pathway involved in the generation of compensatory movements in response to flowfields (for review see Simpson 1984), thereby facilitating retinal image stabilization, which is necessary for normal visual function (Nakayama 1981; Owen and Lee 1986; Westheimer and McKee 1975). In birds, the nucleus of the basal optic root (nBOR) and the nucleus lentiformis mesencephali (LM) comprise the AOS. In pigeon and chicken, most neurons in these structures exhibit direction selectivity in response to large stimuli rich in visual texture (random dot patterns) moving in the contralateral visual field (Britto et al. 1981; Burns and Wallman 1981; Gioanni ct al. 1984; Morgan and Frost 1981; Winterson and Brauth 1985; Wylie and Frost 1990a). In pigeons, nBOR neurons preferring upward, downward, and backward (nasal to temporal) directions are equally represented (Wylie and Frost 1990a), whereas in the LM, most neurons prefer forward motion (Winterson and Brauth 1985; see also McKenna and Wallman 1981, 1985).

Because self-motion results in flowfields across both retinas, one would expect that at some point in the AOS, neurons would integrate binocular flowfield information. In this way flowfields resulting from self-translation and selfrotation could be distinguished. For example, in lateralcyed animals such as the pigeon, a neuron preferring upward motion in both eyes would encode the flowfield resulting from a downward translation (descent) of the bird. In contrast, a neuron preferring upward and downward motion in the opposite eyes would encode the flowfield resulting from roll, a self-rotation. On the basis of the direction preferences of neurons in the AOS, in addition to descent and roll cells, one might postulate the existence of neurons that encode ascent (upward translation; down in both eyes), forward translation (backward in both eyes), backward translation (forward in both eyes), and yaw (horizontal rotation; forward and backward in opposite eyes). In the nBOR a small subpopulation of neurons do have binocular receptive ficlds and respond best to either self-translation or self-rotation (Wylie and Frost 1990b).

On the basis of the projections of the avian AOS, one might also expect to find neurons that distinguish selftranslation and self-rotation in the vestibulocerebellum $(\mathrm{VbC})$. The pigeon $\mathrm{VbC}$ includes the ventral part of folium IXc,d [ ventral uvula; folium IXb according to the nomenclature of Arends and Zeigler (1991a)], folium X (nodu- 
lus), and the auricle (flocculus), a lateral extension of folia IXc,d and X (Arends and Zeigler 1991a; see also Correia et al. 1983; Schwarz and Schwarz 1983, 1986; Whitlock 1952 ). Mossy fibers from the LM and nBOR project bilaterally to folium IXc,d, including the auricle, and a few synapse in folium X (Brecha et al. 1980; Clarke 1977). The nBOR and LM also project bilaterally to the caudal pole of the medial column of the inferior olive (IO) (Bodnarenko and McKenna 1987; Brecha et al. 1980), which in turn projects to the contralateral VbC (Arends and Voogd 1989; Freedman et al. 1977). Thus it is possible that the climbing fibers from the IO to the $\mathrm{VbC}$ are conveying information about flowfields in both eyes.

In various spccics it has been shown that the complex spike (CS) activity of Purkinje cells in the VbC is modulated by wholefield visual motion (Ansorge and GrusserCornehls 1977; Blanks and Precht 1983; Ghelarducci et al. 1975; Graf et al. 1988; Kano et al. 1990a,b; Kusunoki et al. 1990; Miyashita 1979; Precht et al. 1976; Shojaku et al. 1991; Simpson and Alley 1974; Simpson and Hess 1977; Simpson et al. 1989a,b; Waespe and Henn 1981). In the
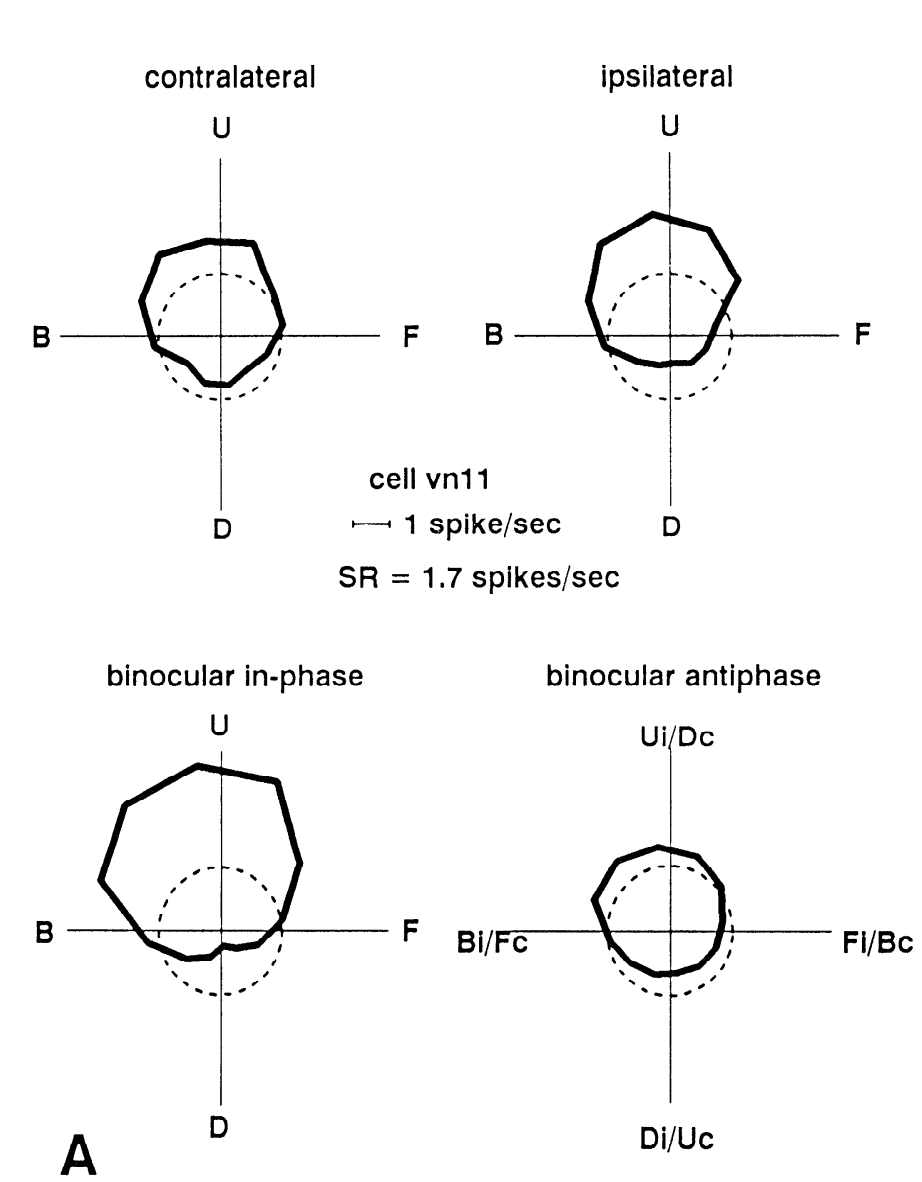

lateral-eyed rabbit, climbing fiber inputs to Purkinje cells with binocular receptive fields encoding rotational flowfields have been described (Graf et al. 1988; Kano et al. 1990a,b; Kusunoki et al. 1990; Leonard et al. 1988; Shojaku et al. 1991; Simpson et al. 1989a,b), but CS activity encoding visual translation was not found. [Graf et al. (1988) found that the simple spike activity of a few Purkinje cells responded best to opposite directions of rotation in the two eyes. They suggested that under natural viewing conditions the simple spike activity of these cells would respond better to visual translation than rotation.] In the frog cerebellum, Ansorge and Grusser-Cornehls (1977) found some neurons that preferred forward wholefield motion in both eyes and thus encoded backward translation.

In birds, electrophysiological studies have shown that the auditory, somatosensory, proprioceptive, visual, and vestibular systems are represented in the pigeon cerebellum (Clarke 1974; Gross 1970; Schwarz et al. 1978; Whitlock 1952; Wilson et al. 1974). Of these studies, only Schwarz et al. (1978) and Wilson et al. (1974) studied the VbC; however, neither investigated responses to visual stimuli. It was

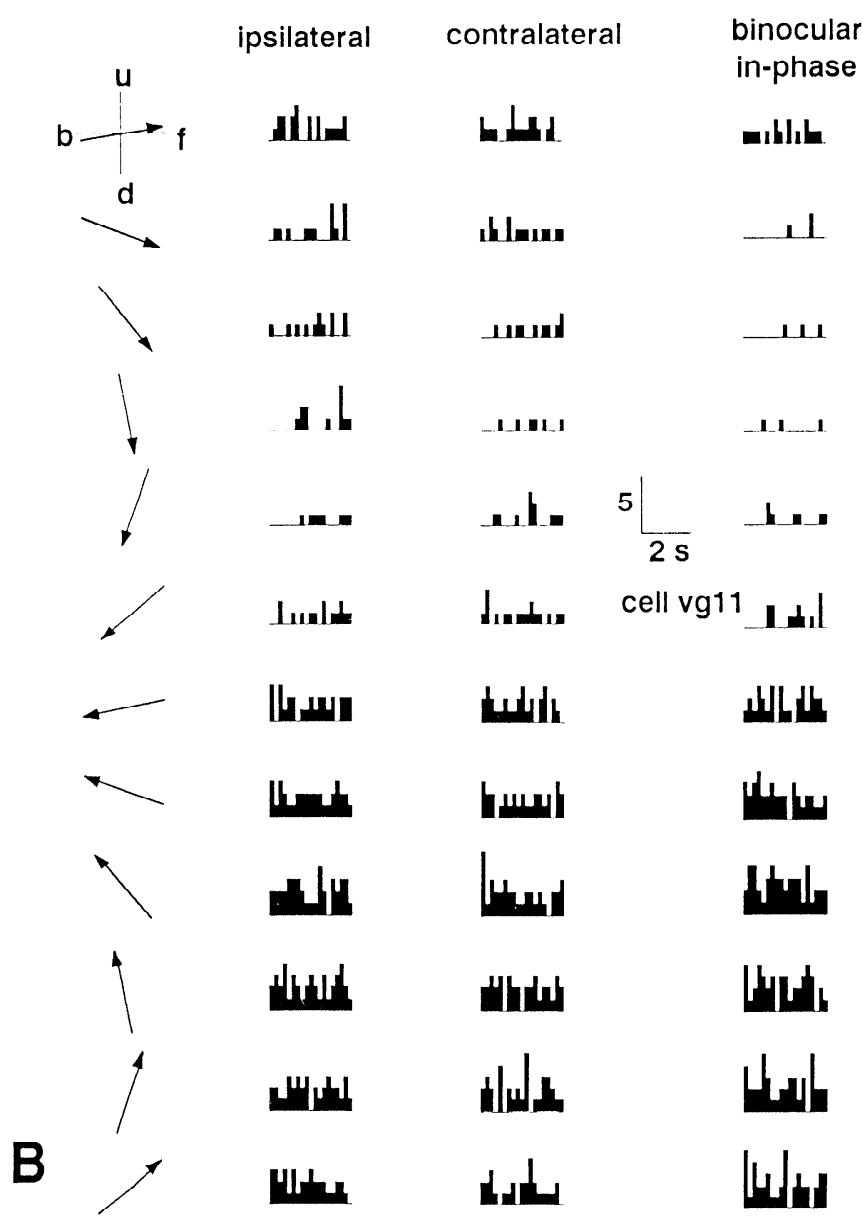

FIG. 1. Direction selectivity of complex spike (CS) activity of 2 descent Purkinje cells in pigeon vestibulocerebellum $(\mathrm{VbC})$ in response to largefield motion. $A$ : for 1 cell, directional tuning curves for ipsilateral, contralateral, binocular in-phase, and binocular antiphase stimulation are shown. Firing rate as a function of direction of largefield motion is plotted in polar coordinates. Dotted circles represent spontaneous rate (SR). B: for a 2 nd cell, peristimulus time histograms (PSTHs) in response to largefield motion for ipsilateral, contralateral, and binocular in-phase stimulation are shown. Visual horizontal ( $f, b$ ) is based on normal orientation of pigeon's head (Erichsen et al. 1989). Arrows indicate direction of motion. Calibration mark, 5 spikes, $2 \mathrm{s.} \mathrm{u}, \mathrm{d}, \mathrm{b}$, and f are upward, downward, backward (nasal to temporal), and forward motion, respectively. See text for details. 
the purpose of this study to characterize the response properties of neurons in the pigeon $\mathrm{VbC}$ to largefield visual motion. A preliminary report of this study has been published (Wylie and Frost 1991).

This research was part of a Ph.D. dissertation by Douglas R. Wylie.

\section{METHODS}

The methods reported herein conformed with the guidelines established by the Canadian Council on Animal Care and the Queen's University Animal Care Committee. Experiments were performed on 43 adult homing pigeons obtained from a local supplier. Pigeons were anesthetized with $10 \mathrm{ml} / \mathrm{kg}$ Urethane $(20 \%)$ or a ketamine-xylazine mixturc $(50 \mathrm{mg} / \mathrm{kg}$ ketamine; $5 \mathrm{mg} / \mathrm{kg}$ xylazine). Supplemental doses were administered as necessary. The birds were placed in a stereotaxic instrument with modified beak and ear bars such that the orientation of the skull conformed to the atlas of Karten and Hodos (1967). A section of bone and dura was removed from the left side of the skull, exposing the dorsal surface of folia VI, VII, and VIII. The size of the exposure measured up to $4 \mathrm{~mm}$ rostrocaudally, and $\sim 1.5 \mathrm{~mm}$ mediolaterally. With vertical penetrations the $\mathrm{VbC}$ could be sampled from 1.0 to $2.3 \mathrm{~mm}$ lateral to the midline. More lateral areas were sampled by orienting the electrode $10^{\circ}$ laterally and, in one animal, by exposing the left flocculus through center of the intact anterior canal.

\section{Stimulus presentation and extracellular recording}

Extracellular recordings were made with glass-insulated tungsten microelectrodes ( 5 to $10-\mu \mathrm{m}$ exposed tips), which were advanced in $5-\mu \mathrm{m}$ steps with a motorized hydraulic microdrive (Frederick Haer). The signal was amplified, filtered, fed through a window discriminator, displayed on an oscilloscope, and played over an audiomonitor. The window discrimination produced standardized square-wave pulses, each representing a single spike, which were stored in a computer to produce peristimulus time histograms (PSTHs).

A largefield random dot stimulus that measured approximately $100^{\circ} \times 100^{\circ}$ was fed to two projection monitors (model EDP 57; Electrohome), and the two identical stimuli were backprojected onto two tangent screens. The screens were placed parallel to each other on either side of the bird's head, $\sim 55 \mathrm{~cm}$ from each eye. Each screen was placed approximately at the center of the monocular visual field. For 30 experiments the largefield stimuli were generated by an image processing system (model 270; Grinnell) hosted by a PDP 11/23 computer (see Frost et al. 1988 for details). This random dot pattern was $50 \%$ black, $50 \%$ white, with a dot size of $\sim 0.4^{\circ}$. For the remaining 13 experiments, the largefield dot stimulus was produced by a Silicon Graphics IRIS-4D/ 310 GTX computer. The backprojected stimulus consistcd of 1,000 white dots, each measuring $\sim 1^{\circ}$ in diameter, randomly dispersed across a black background measuring $\sim 100^{\circ} \times 100^{\circ}$
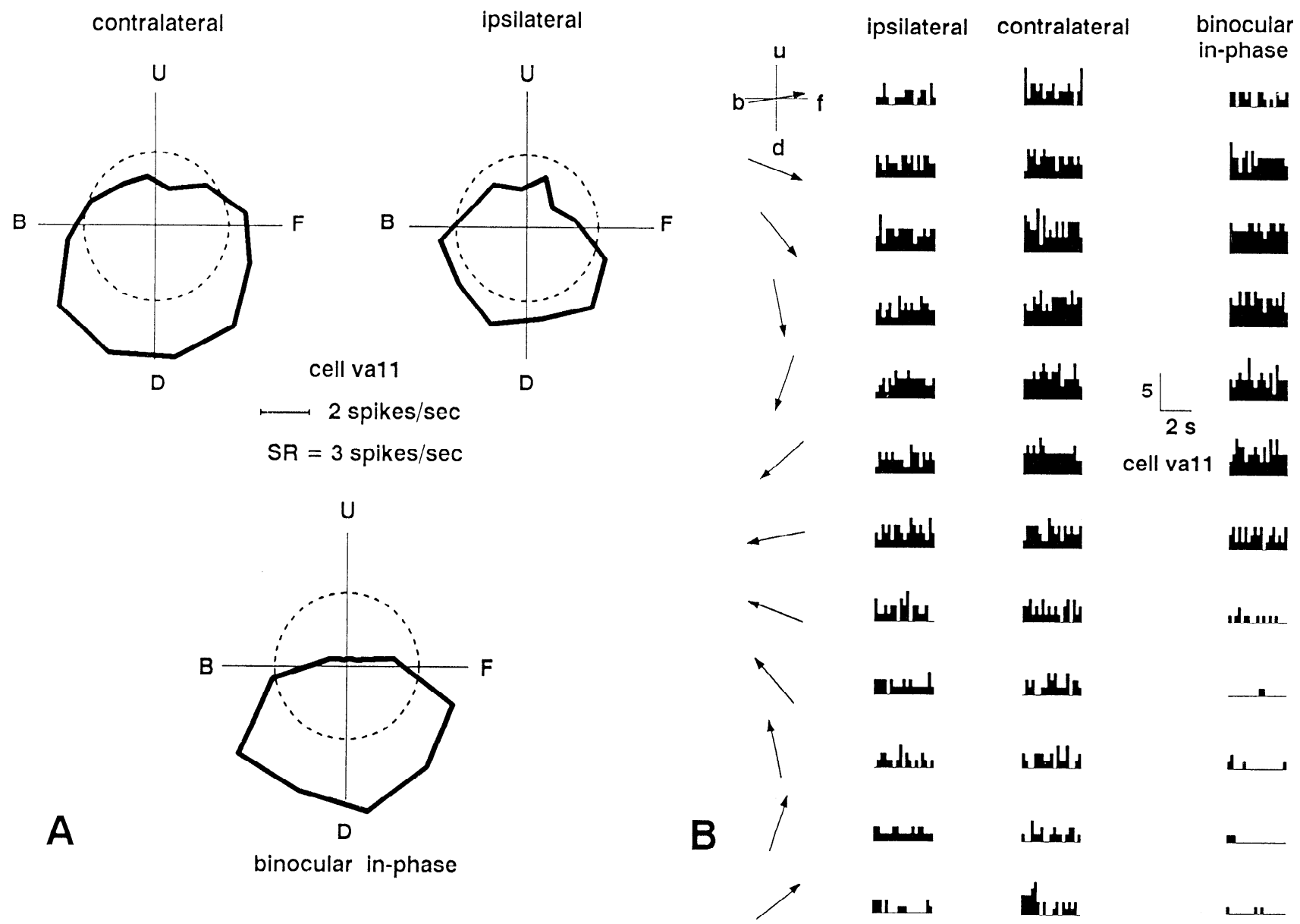

FIG. 2. Direction selectivity of CS activity of an ascent Purkinje cell in pigeon $\mathrm{VbC}$, in response to largefield motion. $A$ : directional tuning curves for ipsilateral, contralateral, and binocular in-phase stimulation are shown. $B$ : PSTHs in response to largefield motion for ipsilateral, contralateral, and binocular in-phase stimulation for same cell are shown. Calibration mark, 5 spikes, $2 \mathrm{~s}$. Sec text for details. 
Both methods of producing the largefield stimuli involved backprojecting the images onto two tangent screens on either side of the bird. For both stimuli, the speed of largefield motion averaged $3.9^{\circ} / \mathrm{s}$; however, because tangent screens were used there was a velocity gradient ranging from $2.3^{\circ} / \mathrm{s}$ at the periphery to $5.3^{\circ} / \mathrm{s}$ at the center

Directional tuning curves were obtained by moving the largefield stimulus in 12 different directions, $30^{\circ}$ apart. An average firing rate was obtained from 5-10 sweeps of each direction, each lasting 4-10 s. The directional tuning curves were performed separately for each eye (monocular) or with binocular stimulation. The binocular directional tuning curves were performed with the direction of motion either the same in both eyes [in-phase; e.g., ipsi $=$ upward, contra $=$ upward; ipsi $=$ backward (nasal to temporal $)$, contra $=$ backward $]$ or with the direction of motion opposite in the two eyes (antiphase; e.g., ipsi $=$ upward, contra $=$ downward; ipsi $=$ forward, contra $=$ backward $)$.

Preferred and nonpreferred directions were obtained by calculating the mean vector from the directional tuning curves (Burns and Wallman 1981; Grasse and Cynader 1982). The mean vector was rotated $38^{\circ}$ to correct for the position of the head in the stereotaxic device. The corrected position represents the normal orientation of the bird's head during flying, walking, and perching (Erichsen et al. 1989).
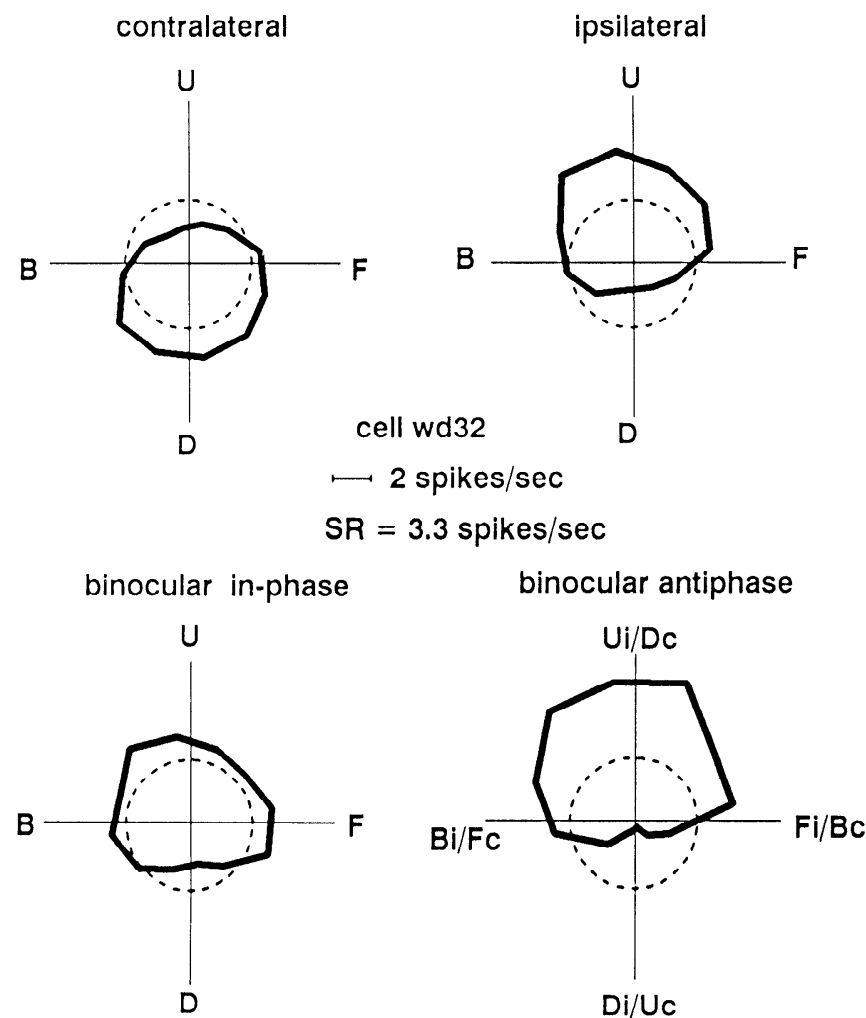

A

FIG. 3. Direction selectivity of CS activity of 2 roll Purkinje cells in pigeon VbC, in response to largefield motion. $A$ : for 1 cell, directional tuning curves for ipsilateral, contralateral, binocular in-phase, and binocular antiphase stimulation are shown. $B$ : for a 2 nd cell, PSTHs in response to largefield motion for ipsilateral, contralateral, and binocular antiphase stimulation are shown. Solid single-headed arrows indicate direction of motion for ipsilateral and contralateral stimulation. For binocular antiphase stimulation, solid and broken lines of double-headed arrow represent directions of motion in ipsilateral and contralateral eyes, respectively. Calibration mark, 5 spikes, 2 s. Ui/Dc, ipsi-up, contra-down; Di/Uc, ipsidown, contra-up; Fi/Bc, ipsi-forward, contra-backward; Bi/Fc, ipsi-backward, contra-forward. See text for details.

\section{Histology}

On some penetrations, marking lesions were made electrolytically at the recording sites ( $10 \mu \mathrm{A}$ for $10 \mathrm{~s})$. At the end of each experiment the animals were administered a lethal dose of pentobarbital sodium $(100 \mathrm{mg} / \mathrm{kg})$ and immediately perfused transcardially with $90 \mathrm{ml}$ of phosphate buffered saline (PBS), followed by $90 \mathrm{ml}$ of paraformaldehyde (4\% in PBS). The brains were stored overnight in the paraformaldehyde, then stored in a sucrose solution (30\% in PBS) until the brain sank. Sagittal or transverse sections through the cerebellum ( $30 \mu \mathrm{m}$ thick $)$ were cut in a cryostat, mounted, dried, and then stained with blue thionine or cresyl violet. Camcra lucida drawings were used to reconstruct the electrode tracks.

\section{RESULTS}

Recordings were obtained from 235 cells, located throughout folia IX and X of the cerebellum, that were responsive to largefield visual stimuli. Units were classified as originating from either Purkinje cells $(n=218)$ or mossy fibers (MFs; $n-17$ ). MF activity was identified by the high spontaneous rates (SR) ( 5 to 40 spikes/s) and histological confirmation in the granular layer. These units were quite
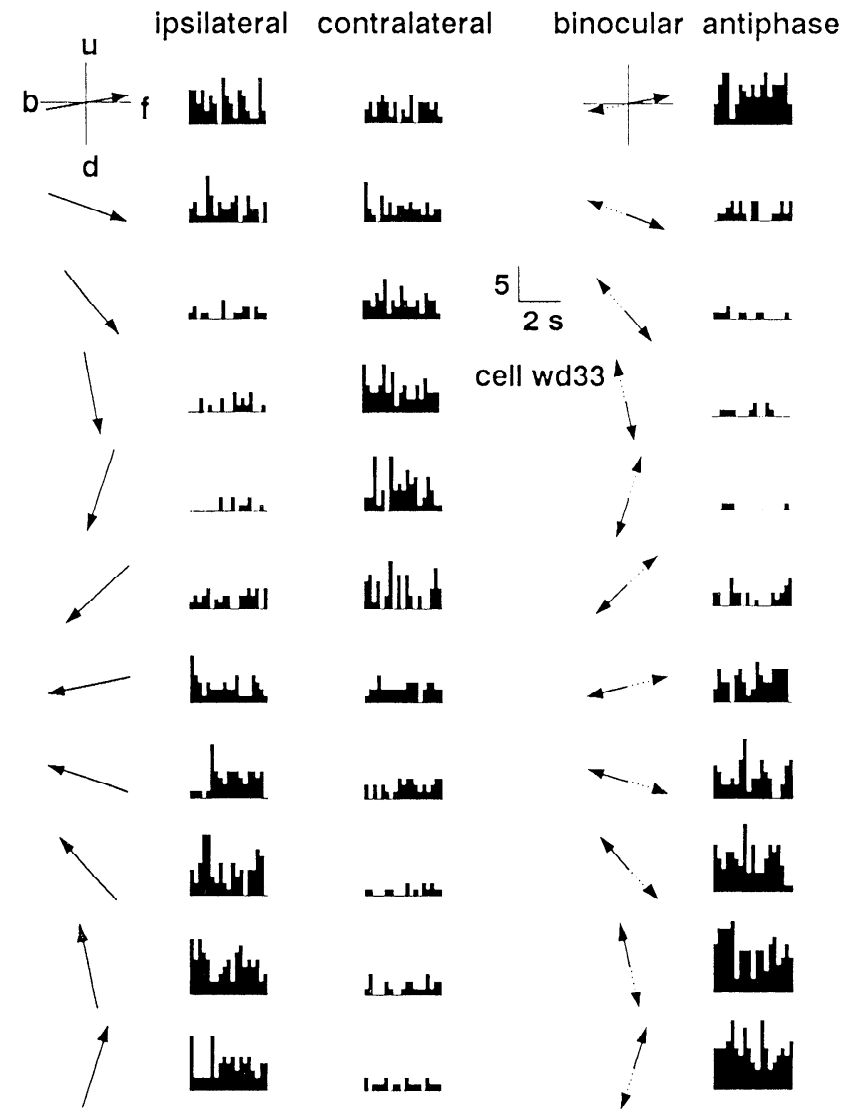

cell wd33

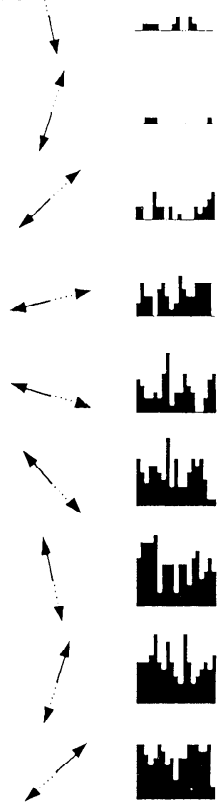


difficult to isolate, and units were lost if the electrode was advanced $>20 \mu \mathrm{m}$. Purkinje cells were identified by the presence of the CS activity and histological identification in the Purkinje cell laycr. In folia IXc,d and X, $\sim 85 \%$ of Purkinje cells were visually responsive. The SR of CS activity averaged 2.3 spikes/s (range 0-9.8 spikes/s).

\section{Purkinje cells}

CS activity of Purkinje cells in folia IX and X exhibited direction selectivity in response to the largefield motion. However, the movement of small spots or bars was ineffective in modulating CS activity. The fact that the neurons integrate information over large areas, combined with the low firing rate of CS activity, made a determination of the approximate size of the receptive fields and the position of the boundaries impossible. Simple spike (SS) activity was usually not modulated by the largefield stimulus, although, for the few neurons that did show SS modulation, SS and CS activity had opposite direction preferences. Further description will be confined to CS activity.

With the exception of 19 units, all were binocular. The binocular cells could be divided into four groups based on direction selectivity: descent neurons $(n=112)$ preferred upward motion in both eyes; ascent neurons $(n=14)$ pre-

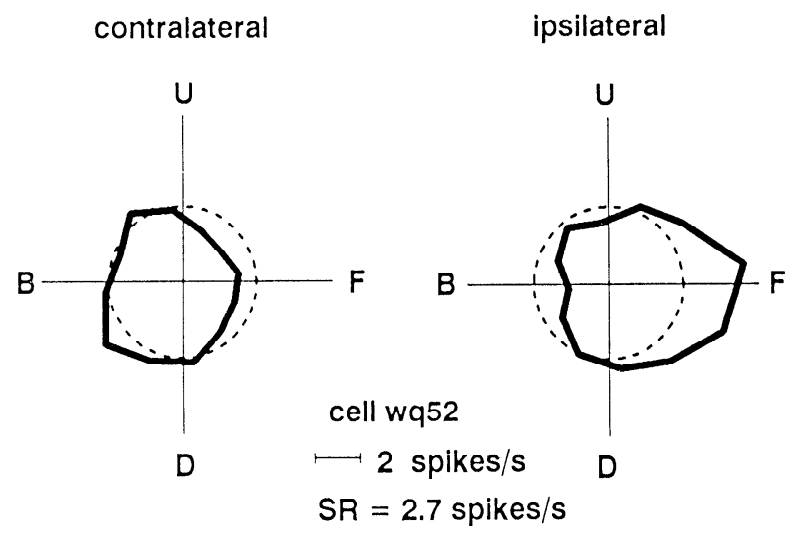

binocular in-phase

binocular antiphase
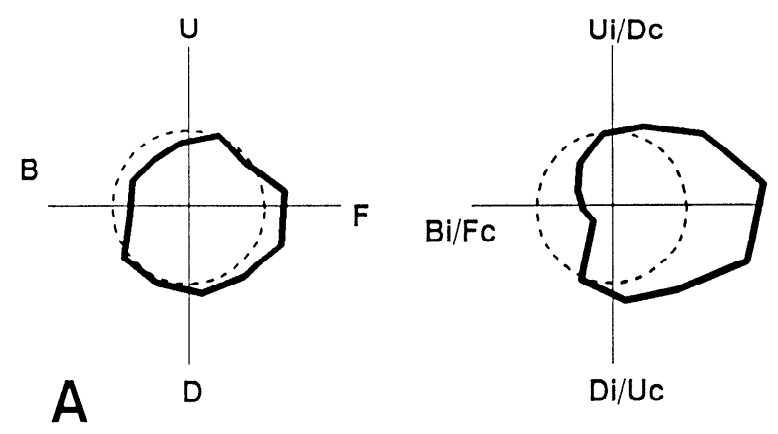

$\mathrm{Fi} / \mathrm{BC}$

\footnotetext{
FIG. 4. Direction selectivity of CS activity of 2 yaw Purkinje cells in pigeon VbC, in response to largefield motion. $A$ : for 1 cell, directional tuning curves for ipsilateral, contralateral, binocular in-phase, and binocular antiphase stimulation are shown. $B$ : for a 2 nd cell, PSTIIs in response to largefield motion for ipsilateral, contralateral, and binocular antiphase stimulation are shown. Calibration mark, 10 spikes, $2 \mathrm{~s}$. See text for details.
}

ferred downward motion in both eyes; roll neurons $(n=$ 33 ) preferred upward and downward motion in the ipsilateral and contralateral eyes, respectively; and yaw cells $(n-$ $40)$ preferred forward (temporal to nasal) and backward motion in the ipsilateral and contralateral eyes, respectively.

Typical CS responses to monocular and binocular largefield motion in 12 different directions are shown for Purkinje cells from each class in Figs. 1-4. Directional tuning curves for a single unit are shown in $A$ of each figure, and PSTHs for a single unit are shown in $B$ of each figure. The responses to monocular stimulation show that descent neurons are excited by upward motion in both eyes and inhibited by downward motion in both eyes (Fig. 1); ascent neurons are excited by downward motion and inhibited by upward motion in both eyes (Fig. 2); roll neurons are excited by upward and downward motion in the ipsilateral and contralateral eyes, respectively, and inhibited by downward and upward motion in the ipsilateral and contralateral eyes, respectively (Fig. 3); and yaw neurons are excited by forward and backward motion in the ipsilateral and contralateral eyes, respectively, and inhibited by backward and forward motion in the ipsilateral and contralateral eyes, respectively (Fig. 4).

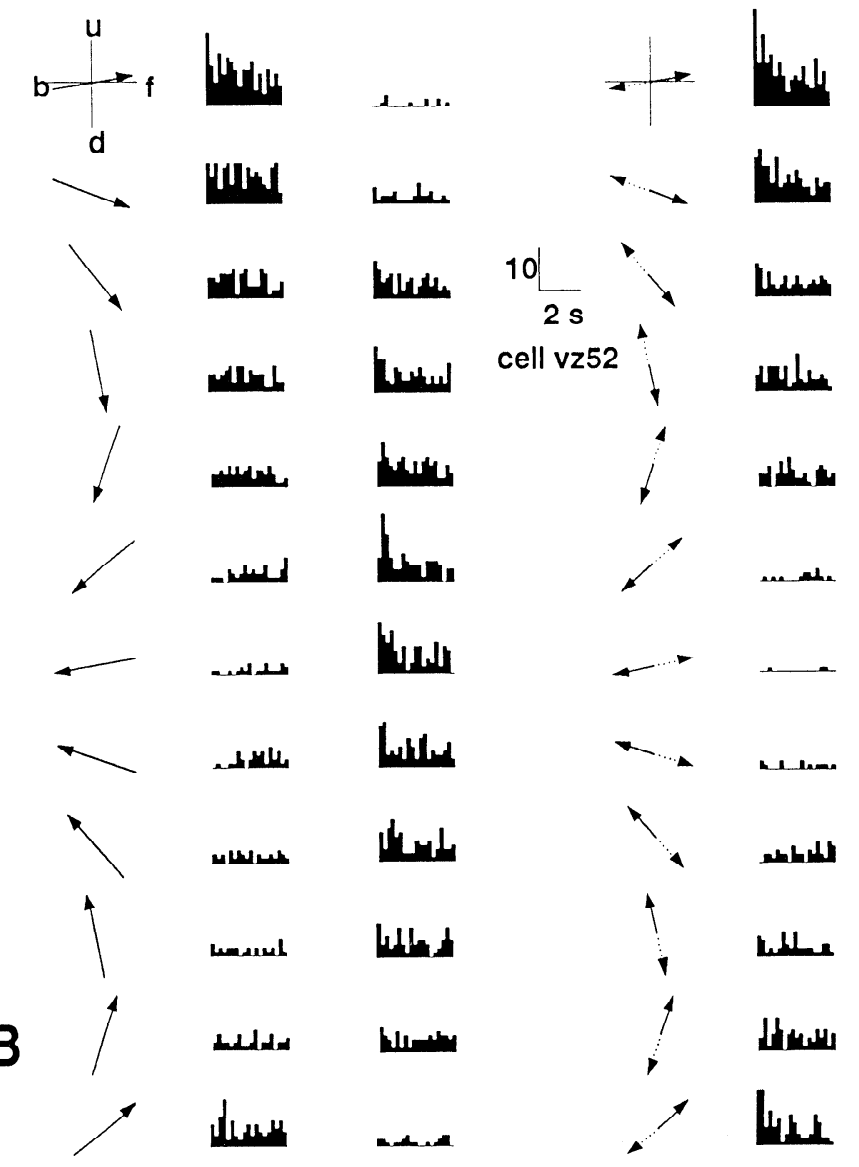




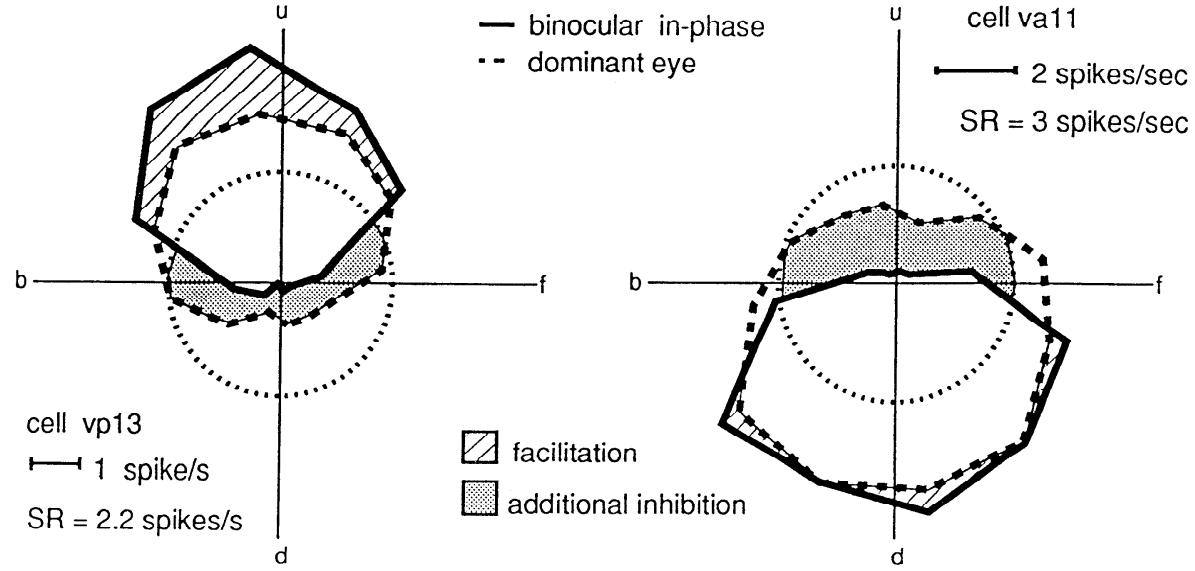

A

B

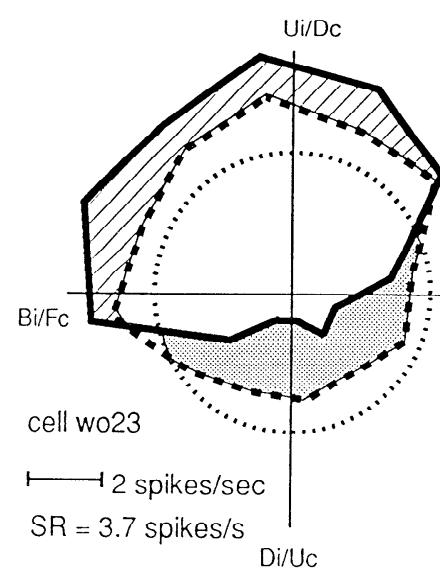

C

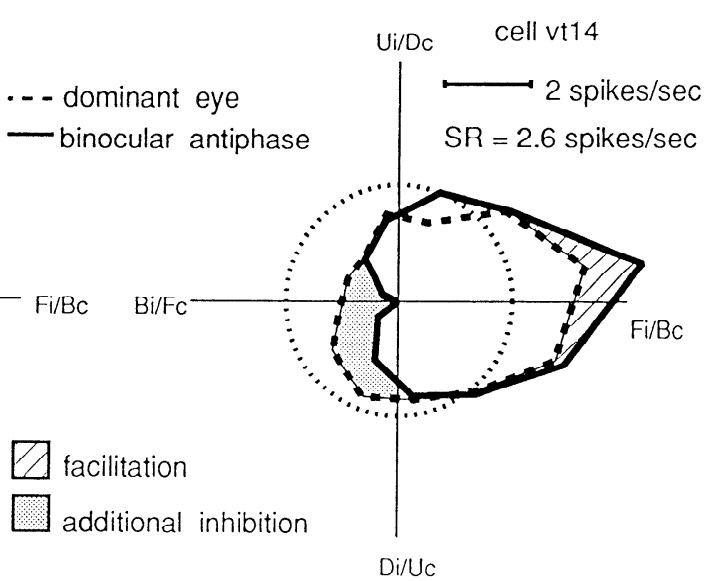

D
FIG. 5. Binocular facilitation of $\mathrm{CS}$ activity of descent $(A)$, ascent $(B)$, roll $(C)$, and yaw $(D)$ Purkinje cells. Directional tuning curves for binocular in-phase stimulation $(A$ and $B)$ and binocular antiphase stimulation $(C$ and $D)(-)$ and stimulation of dominant eye (-- - ; ipsilateral for $A, C$, and $D$, contralateral for $B$ ) are compared. See text for details.

\section{Binocular facilitation}

For the descent and ascent cells, binocular in-phase stimulation resulted in the greatest modulation of CS activity, and binocular antiphase stimulation resulted in little modulation (see Figs. 1 and 2). This is more clearly illustrated in Fig. 5, $A$ and $B$, which compares the tuning curve for binocular in-phase stimulation with that of monocular stimulation of the dominant eye. For the descent cell (Fig. 5A), upward motion in both eyes clearly resulted in more excitation relative to upward motion in the dominant eye alone (binocular facilitation), and downward motion in both eyes resulted in more inhibition than downward motion in the dominant eye ( binocular inhibition ). Binocular facilitation and binocular inhibition are also apparent for the ascent cell (Fig. 5B).

Similarly, for the roll and yaw cells, binocular antiphase stimulation resulted in the greatest depth of modulation, whereas binocular in-phase stimulation had little effect ( see Figs. 3 and 4). Figure 5, $C$ and $D$, compares the binocular antiphase tuning curve to that for the dominant eye for a yaw and a roll cell. Binocular facilitation and binocular inhibition are apparent for both cells.

To quantitatively compare the responses to binocular stimulation and monocular stimulation of the dominant eye, we calculated the depth of modulation in response to

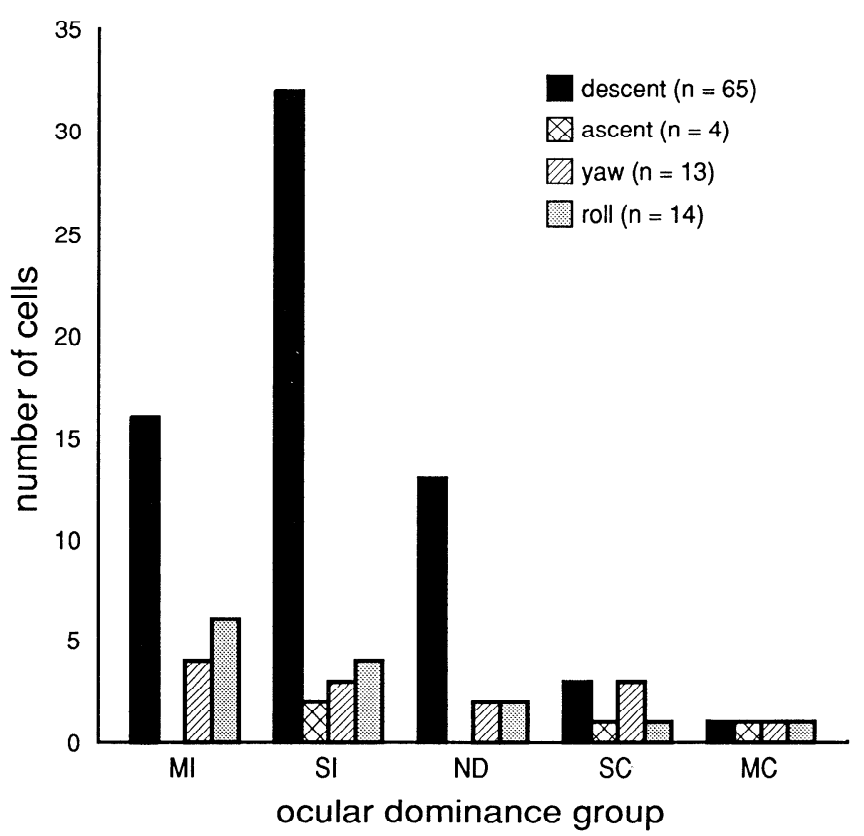

FIG. 6. A frequency histogram of ocular dominance group for ascent, descent, roll, and yaw cells. MI, markedly ipsilateral; MC, markedly contralateral; SI, slightly ipsilateral; SC, slightly contralateral; ND, no dominance. See text for ocular dominance group assignment. Note that most cells have an ipsilateral dominance. 
ipsilateral
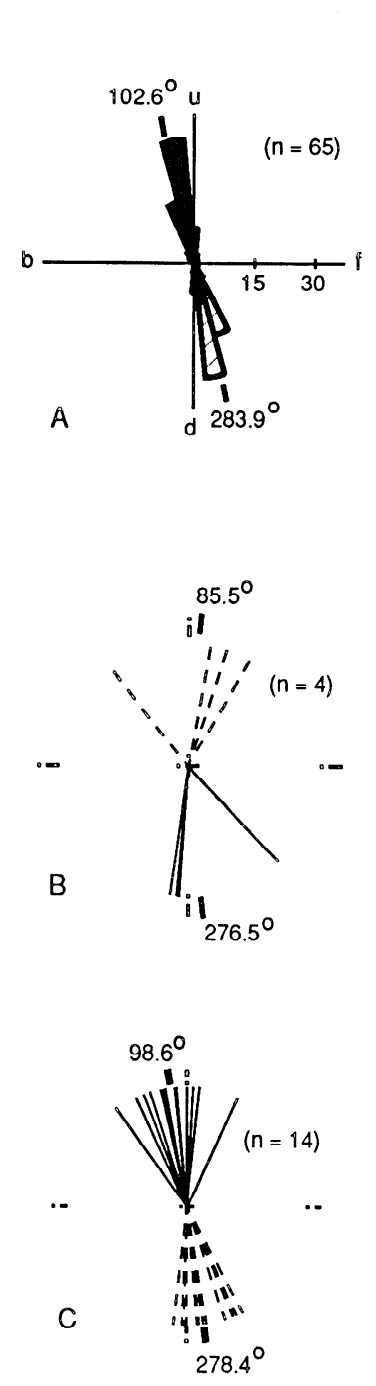

: $\quad(n=13)$

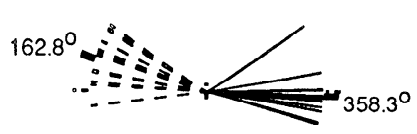

D : contralateral
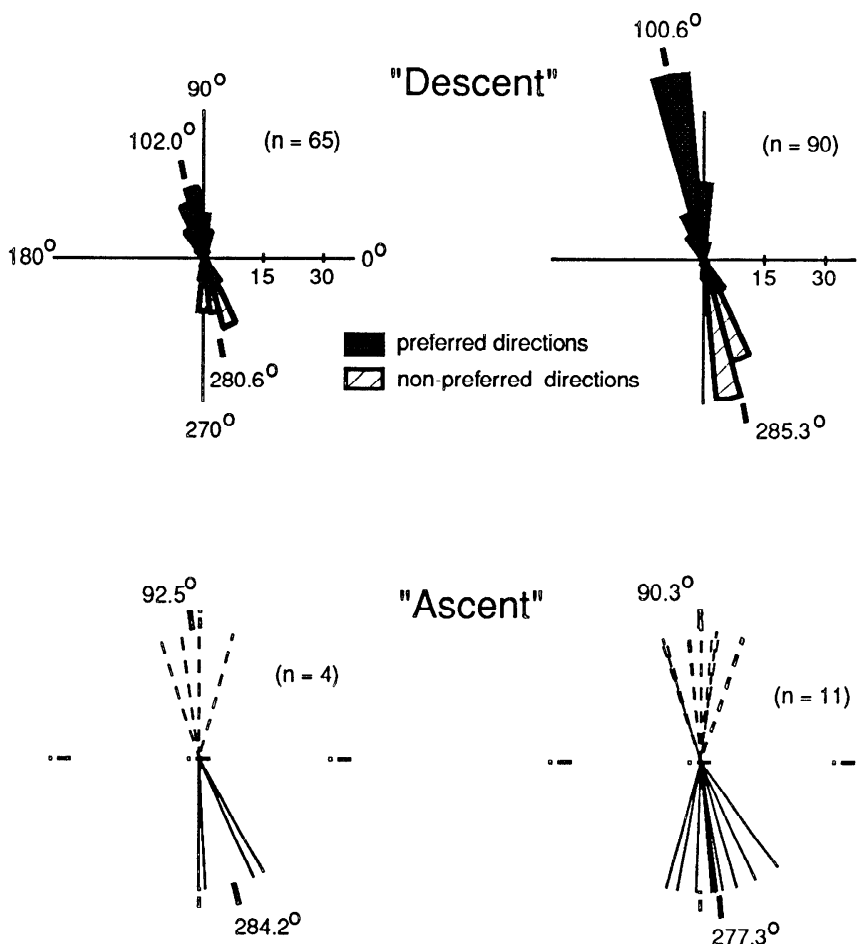

"Ascent"
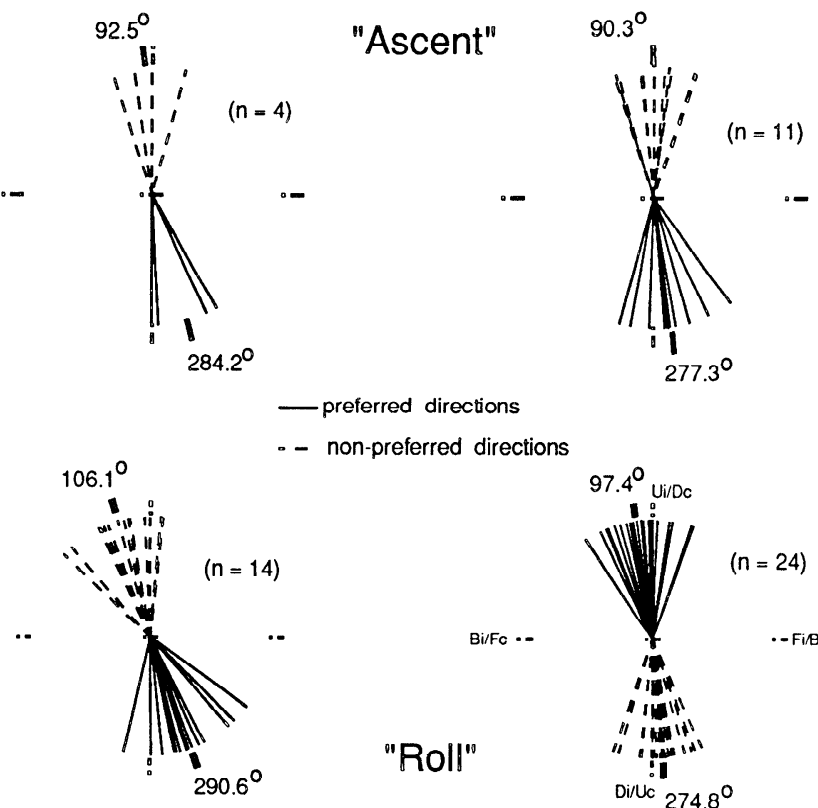

- preferred directions

- non-preferred directions
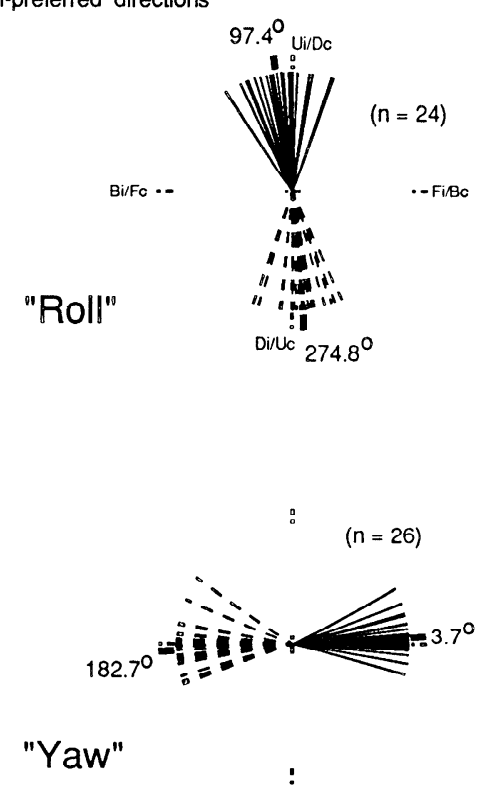

FIG. 7. Distribution of preferred and nonpreferred directions of CS activity of descent $(A)$, ascent $(B)$, roll $(C)$, and yaw $(A)$ Purkinje cells in pigeon $\mathrm{VbC}$. Each cell was assigned a preferred and nonpreferred direction from vector analysis of ipsilateral, contralateral, and binocular tuning curves. In $B-D$ solid and broken lines represent preferred and nonpreferred directions of individual cells. In $A$ a polar histogram of frequency of preferred ( $\bullet$ ) and nonpreferred ( $⿴ 囗 ⿱ 一 一)$ ) directions is shown. Means of preferred and nonpreferred vectors are indicated for each cell type under each stimulation condition. See text for details.

binocular stimulation as a ratio of that in response to monocular stimulation of the dominant eye

$$
\mathrm{BR}-\frac{\operatorname{bin}(\text { FR pref }- \text { FR non-pref) }}{\text { mono-dom (FR pref - FR non-pref) }}
$$

where BR is the binocular ratio; bin is the binocular stimula- tion; mono-dom is the monocular stimulation of the dominant eye; FR pref is the firing rate, preferred direction; and FR non-pref is the firing rate, nonpreferred direction. The depth of modulation in response to binocular stimulation was considered greater than that in response to monocular stimulation if the BR was $>1.10$. Across all classes, the BR 
was $>1.10$ for 86 of the 95 cells tested. For these 86 cells the BR averaged 1.49 (range, 1.11-2.58). That is, the depth of modulation in response to binocular stimulation was, on average, $49.1 \%$ (range $11-158 \%$ ) greater than that in response to monocular stimulation of the dominant eye.

\section{Ocular dominance}

A five-point, semiquantitative scale was used to categorize the binocular cells on the basis of the relative depth of modulation to ipsilateral and contralateral stimulation. Cells were classified as displaying marked, slight, or no dominance. The measure used was a ratio of the modulation due to stimulation of the dominant and nondominant eyes

$$
\text { OD }-\frac{\text { dom (FR pref }- \text { FR non-pref })}{\text { non-dom (FR pref FR non-pref) }}
$$

where OD is the ocular dominance ratio; dom is the dominant eye; non-dom is the nondominant eye; FR pref is the firing rate, preferred direction; and FR non-pref; is the firing rate, nonpreferred direction. If $\mathrm{OD}>1.5$, there is a marked dominance; if $1.1<\mathrm{OD}<1.5$, there is a slight dominance; and if OD $<1.1$, there is no dominance. A frequency histogram of the ocular dominance group is shown for all classes in Fig. 6. Note that most cells showed an ipsilateral dominance.

\section{Population analysis}

Within classes, it was apparent that the preferred directions across individual cells were remarkably similar. Figure 7 shows the preferred and nonpreferred directions for descent, ascent, roll, and yaw cells as calculated by vector analysis (Burns and Wallman 1981; Grasse and Cynader

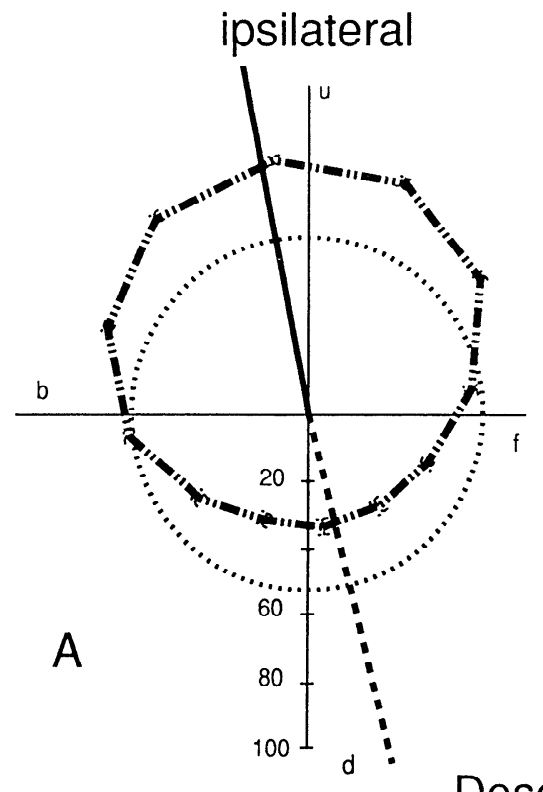

Descent cells $(n=65)$

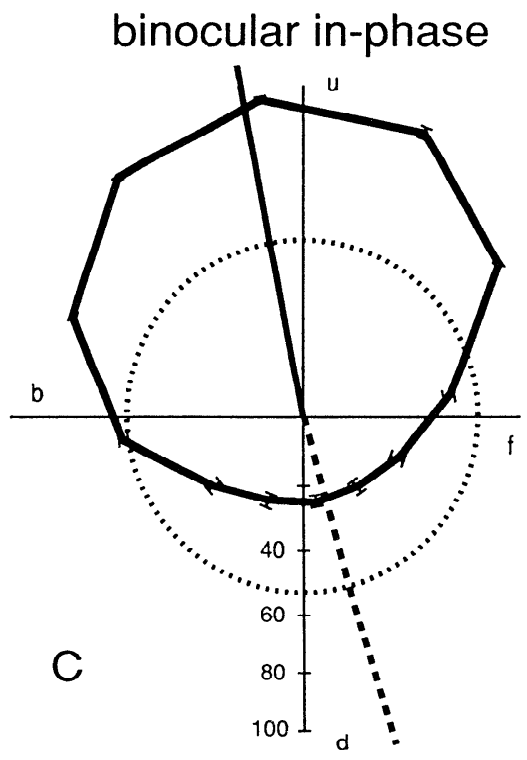

FIG. 8. Mean tuning curves for ipsilateral, contralateral, and binocular in-phase stimulation of descent Purkinje cells in pigeon VbC. For each descent cell, firing rate in response to largefield motion in each direction for ipsilateral, contralateral, and binocular in-phase stimulation was calculated as a percentage of the maximal firing rate. Mean percentage as a function of direction of motion is plotted in polar coordinates for ipsilateral $(A)$, contralateral $(B)$, and binocular in-phase stimulation $(C)$. These are compiled in $D$ for comparison. Error bars represent \pm 1 SE. Dotted circles in $A-C$ and dotted line in $D$ represent mean spontaneous rate. Stippled area in $D$ represents $1 \mathrm{SE}$ above and below the mean SR. Preferred (solid lines) and nonpreferred (broken lines) directions as calculated by vector analysis of the mean tuning curves are shown. See text for details. 
1982 ) of the ipsilateral, contralateral, and binocular tuning curves. In Fig. 7, $B-D$, the preferred (solid lines) and nonpreferred directions (broken lines) for every cell are shown as unit vectors. In Fig. $7 A$ a frequency histogram of the preferred and nonpreferred directions is shown because of the large number of descent cells involved. The mean preferred and nonpreferred directions for each class are also indicated. Note that the preferred and nonpreferred direction cluster tightly about given directions. For the descent cells, the mean preferred (and nonpreferred) directions for ipsilateral, contralateral, and binocular in-phase stimulation are approximately the same, $\sim 10-15^{\circ}$ posterior to the vertical. For the ascent cells (Fig. $7 B$ ), there is less similarity of the mean preferred and nonpreferred directions across the three conditions; however, a much smaller sample is involved. Note that the mean preferred (and nonpreferred) direction for binocular in-phase stimulation is ap- proximately opposite to that for the descent cells. For the roll cells (Fig. $7 \mathrm{C}$ ), the mean preferred (and nonpreferred) directions for ipsilateral and contralateral stimulation are approximately opposite to one another. Moreover, the preferred direction for ipsilateral stimulation and the nonpreferred direction for contralateral stimulation are similar to the preferred direction for the descent cells, i.e., just posterior to vertical. For the yaw cells (Fig. $7 D$ ), with binocular antiphase stimulation the mean preferred and nonpreferred directions are approximately horizontal. However, with respect to monocular stimulation of the yaw cells, the mean preferred (and nonpreferred) vectors for ipsilateral and contralateral stimulation are not opposite to one another. The mean preferred direction for the ipsilateral eye is directly forward; however, for the contralateral eye, the mean preferred direction is $30^{\circ}$ down from directly backward.

Mean normalized tuning curves for ipsilateral, contralat- ipsilateral

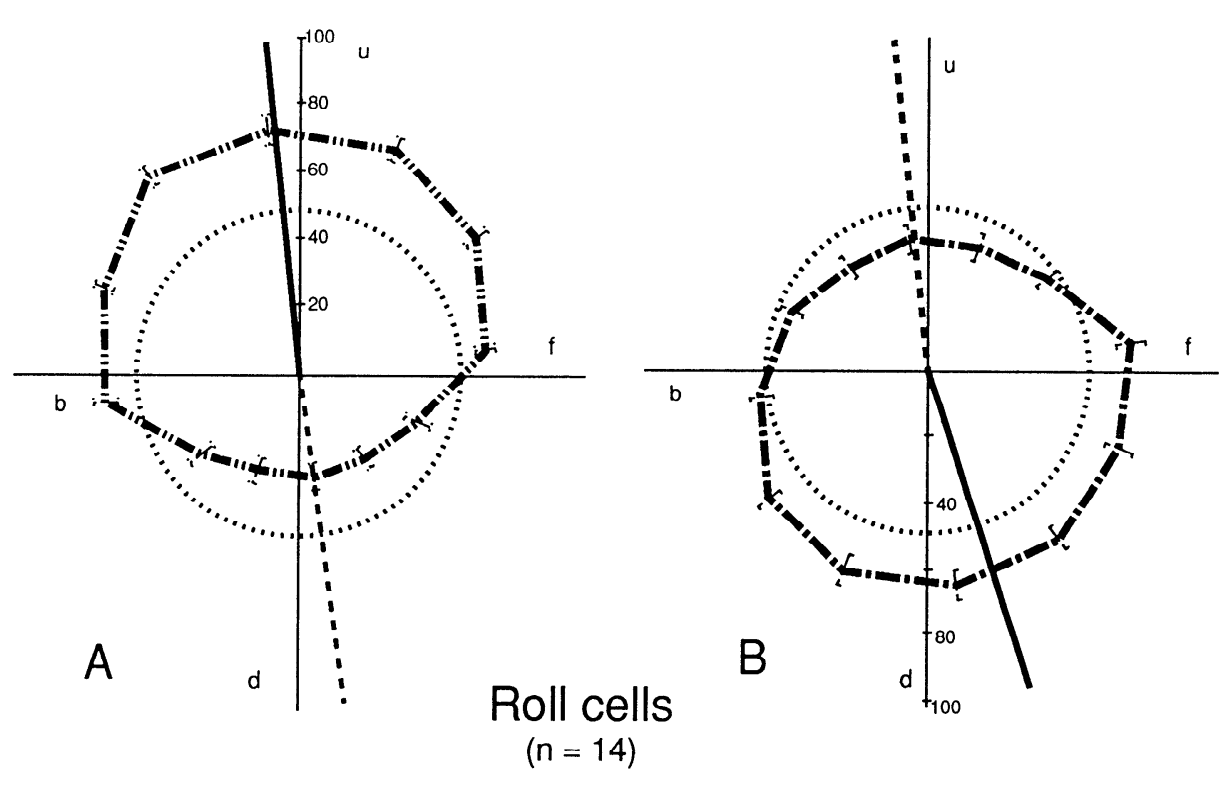

binocular antiphase

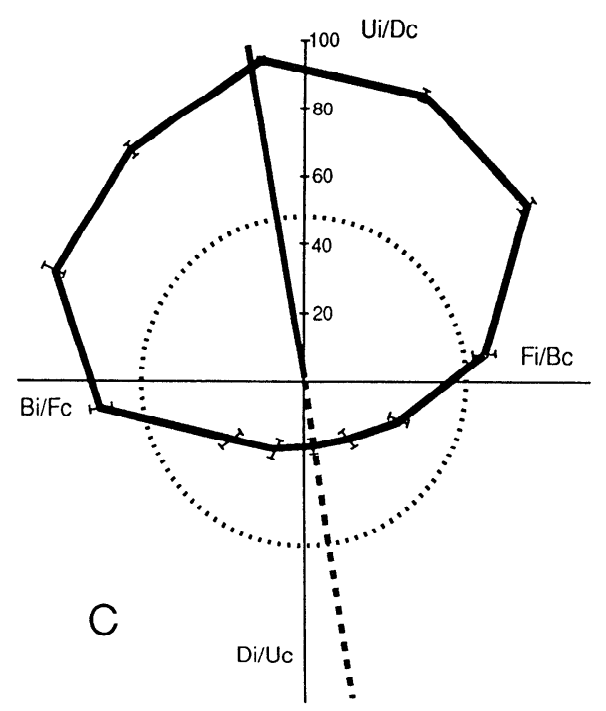

\section{contralateral}

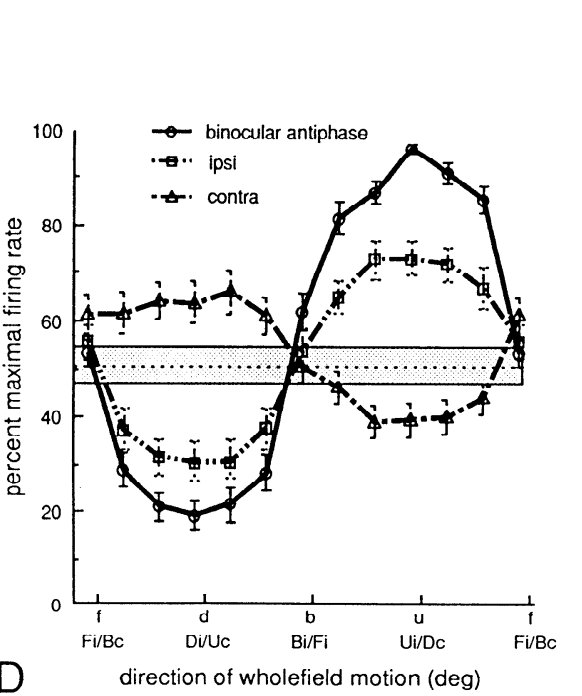

FIG. 9. Mean tuning curves for ipsilateral $(A)$, contralateral $(B)$, and binocular antiphase $(C)$ stimulation of roll Purkinje cells in pigeon VbC. Refer to Fig. 8 for explanation. See text for details. 
eral, and binocular in-phase/ antiphase stimulation are presented in Figures 8, 9, and 10, for the descent, roll, and yaw cells respectively. These were obtained by calculating the firing rate in response to largefield motion in each of the 12 directions as a percentage of the maximal firing rate of the cell (which occurred in response to motion in the preferred direction with binocular stimulation). For every cell, percentages were obtained for each direction for ipsilateral, contralateral, and binocular in-phase/antiphase stimulation. Within functional classes, the mean percentage was calculated for each of the 12 directions under each of the three stimulation conditions. These mean percentages are plotted in polar coordinates for ipsilateral, contralateral, and binocular in-phase/antiphase stimulation. The mean preferred and nonpreferred directions as calculated from vector analysis of the mean tuning curves are also shown. The only cells included were those from which complete ipsilateral, contralateral, and binocular in-phase/antiphase tuning curves were obtained. [ Because of the small number of cells from which complete tuning curves were obtained with monocular stimulation $(n=4)$, a mean normalized tuning curve for ascent cells was not calculated.] For all classes, a slight ipsilateral dominance and binocular facilitation/inhibition is apparent. For the descent cells (Fig. 8), the mean tuning curves for each condition are similar in shape and the preferred (and nonpreferred) directions for ipsilateral, contralateral, and binocular in-phase stimulation are approximately the same, $\sim 10^{\circ}$ posterior to verti$\mathrm{cal}$. In agreement with the vector analysis of individual neurons, for the yaw cells, the preferred (and nonpreferred) directions for ipsilateral and contralateral mean tuning curves are not opposite to one another. The preferred direction for contralateral stimulation is $\sim 30^{\circ}$ down from the horizontal.

\section{Monocular cells}

Recordings were made from 19 Purkinje cells that showed CS modulation in response to largefield stimulation of one eye only. Fifteen cells responded to the ipsilat-

\section{ipsilateral}

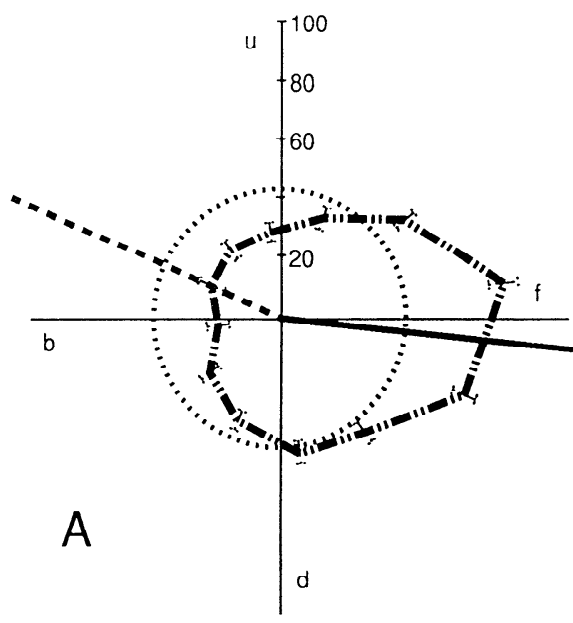

Yaw cells

$(n=13)$

\section{binocular antiphase}
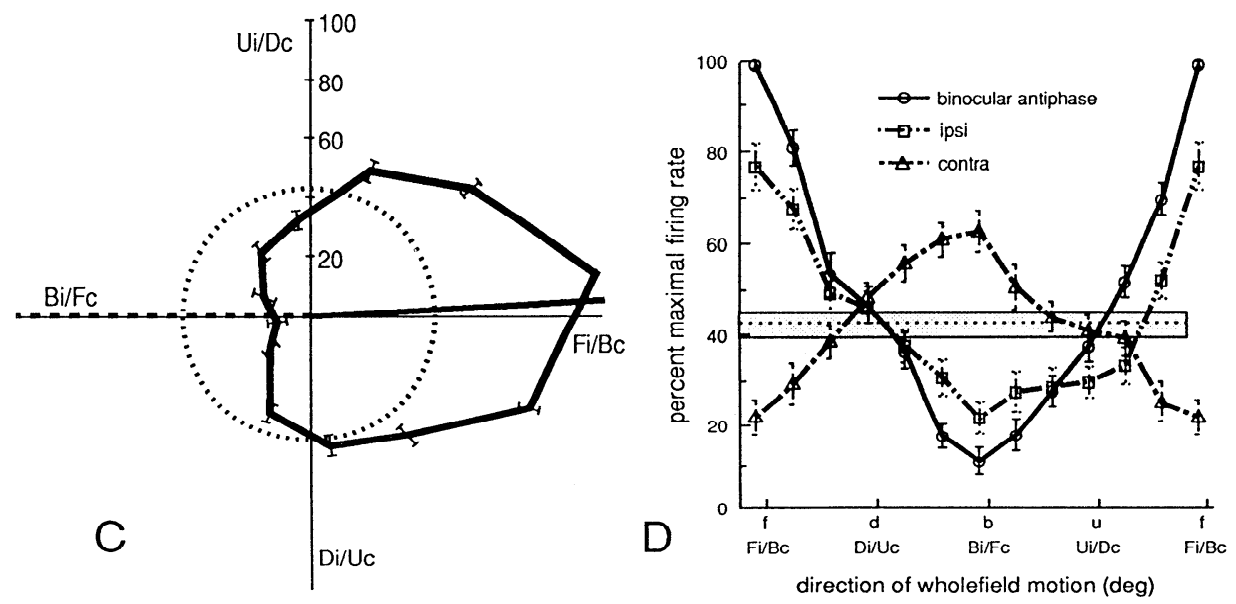

FIG. 10. Mean tuning curves for ipsilateral $(A)$, contralateral $(B)$, and binocular antiphase $(C)$ stimulation of yaw Purkinje cells in pigeon $\mathrm{VbC}$. Refer to Fig. 8 for explanation. See text for details. 
eral cyc alonc, preferring either forward (5), upward (9), or downward largefield motion (1). Four cells responded to the contralateral eye alone; three preferred forward motion and one preferred backward motion.

\section{Functional organization of the CS activity in the $\mathrm{VbC}$}

The locations of 113 binocular and 9 monocular Purkinje cells were histologically confirmed. Six of the monocular cells were located in folium IXa,b [ folium IXa according to the nomenclature of Arends and Zeigler (1991a)], one in the dorsal lamella and five in the ventral lamella. Two monocular cells were located in dorsal IXc,d, and one was located in ventral IXc,d. In contrast, nearly all binocular cells were located in ventral IXc,d $(60)$ or folium X (48), except five that were found in dorsal IXc,d.

As shown in Fig. 11, there was a mediolateral organization of the functional classes of binocular Purkinje cells. The translation cells (descent and ascent) were found medial to the rotation cells (roll and yaw). In Fig. $11 A$ the results of one experiment illustrate this organization. A camera lucida drawing shows the locations of six cells found on three tracks in the same transverse plane. On the two medial tracks, ascent and descent cells were found; but on the laterally placed track, yaw and roll cells were found. In Fig. $11 \mathrm{~B}$, the locations of 113 binocular cells from 24 birds are shown on an unfolded Purkinje layer through folia IXc, d and X. Recording sites were located throughout the mediolateral extent of the $\mathrm{VbC}$, with the exception of a $1-\mathrm{mm}$ strip adjacent to the midline. This area was difficult to explore because of a large midsagittal blood vessel across the dorsal surface of the cerebellum. Ascent and descent cells were located medially, and the roll and yaw cells were found lateral to these. A sharp division is apparent 1.8-2.1 $\mathrm{mm}$ lateral to the midline.

\section{MF Activity}

Seventeen units within the granular layer displaying MF activity responded to the largefield stimulus. These units, presumably granule cells or MF rosettes, had high firing rates, were found in the granular layer, and were extremely difficult to isolate. All of these cells were monocular, 12 ipsilateral and 5 contralateral. The ipsilateral cells preferred either upward (7), downward (2), backward (2), or forward (1) largefield motion. The contralateral cells preferred

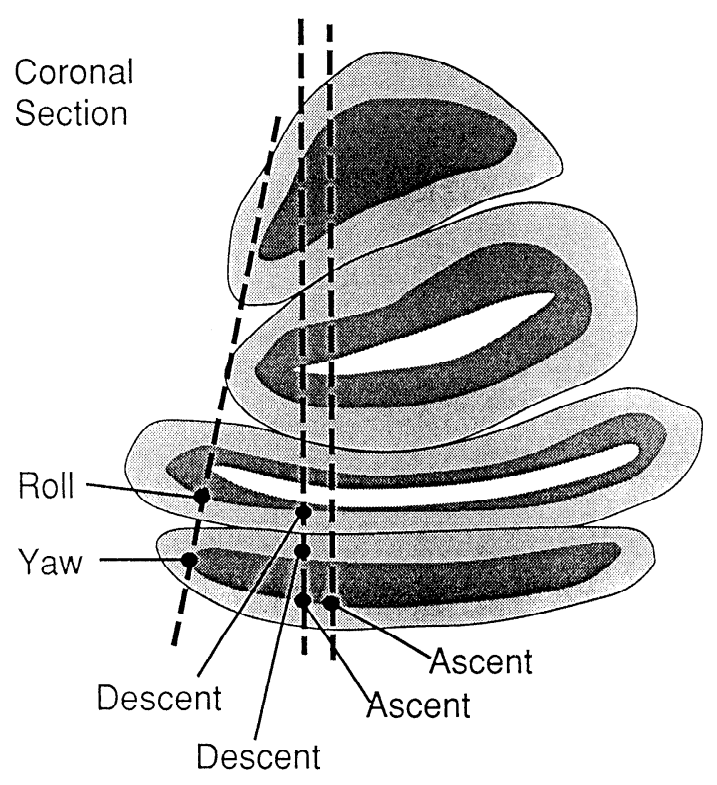

A

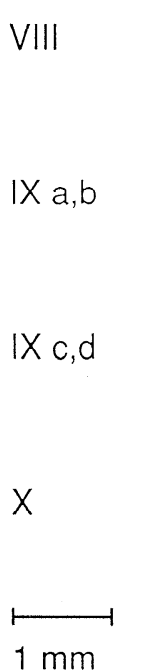

B

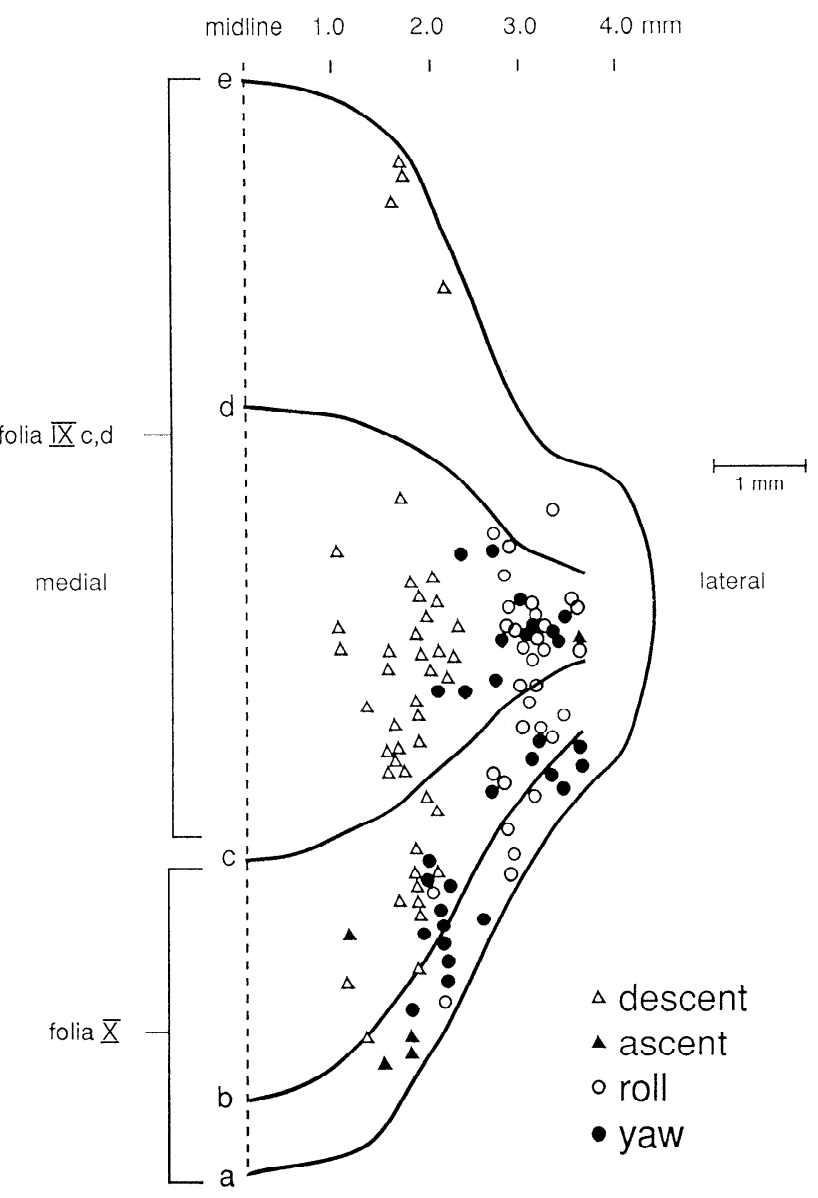

FIG. 11. I ongitudinal organization of CS responses of Purkinje cells in pigeon VbC. $A$ : camera lucida drawing of a transverse scction through cerebellum showing location of 6 recording sites on 3 electrode penetrations. $B$ : location of 113 histologically confirmed recording sites on an unfolded Purkinje layer through folia IXc,d and X, according to functional class. Included are 15 cells from companion paper (Wylie and Frost 1993). These data were compiled from 24 birds. Note mediolateral separation of translation (ascent and descent) cells from rotation ( roll and yaw) cells at $\sim 1.8-2.1 \mathrm{~mm}$ lateral to the midline. 


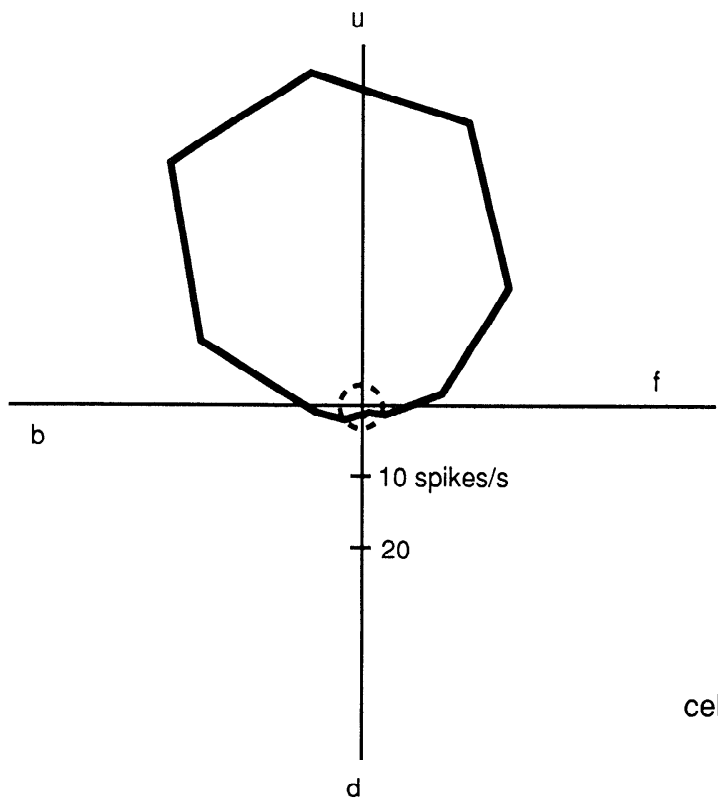

IPSILATERAL

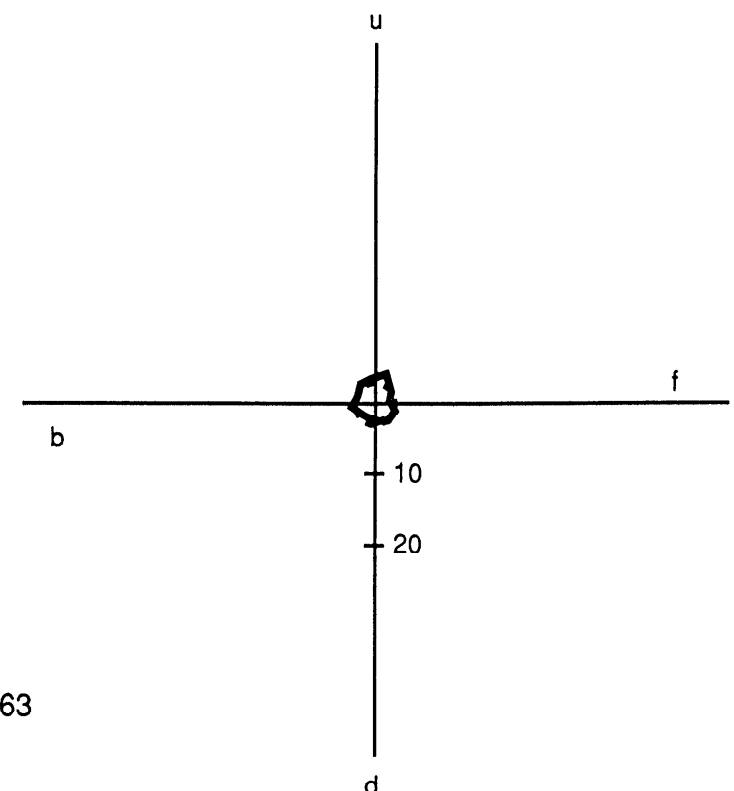

CONTRALATERAL

FIG. 12. Ipsilateral and contralateral direction tuning curves of a mossy fiber unit. Note that unit responds only to monocular stimulation.

upward (3) or downward (2) largefield motion. The directional tuning curve of a representative unit is shown in Fig. 12. Of nine histologically confirmed MF recording sites, all were in folia IX: one was in ventral IXa,b; threc were in dorsal IXc,d; three were at the posterior pole of IXc,d; and two were in ventral IXc,d.

\section{DISCUSSION}

In this study it has been shown that cells in the pigeon cerebellum exhibit direction selectivity in response to largefield motion in the visual fields of one or both eyes. These cells were found throughout the $\mathrm{VbC}$, including the ventral uvula (folium IXc,d ventral lamella), the nodulus (folium $X$ ), and the auricle (flocculus; lateral aspects of folia IXc, d and $X$ ), and to a lesser extent in the dorsal uvula (folium IXc,d dorsal lamella) and folium IXa,b. MF units found throughout folium IX were monocular, as was the CS activity of some Purkinje cells found mainly in the dorsal uvula and folium IXa,b. However, the CS activity of Purkinje cells in the ventral uvula, nodulus, and flocculus exhibited direction selectivity in response to largefield motion in both eyes. The discussion will focus on these binocular cells.

Four classes of binocular cells were distinguished on the basis of the direction preference in each eye. Descent neurons preferred upward largefield motion in the lateral visual fields of both eyes, a visual flowfield that would result from a downward translation (descent) of the animal, as it lands on a perch, for example. Ascent neurons preferred downward largeficld motion in the lateral fields of both eyes, which would result from an upward translation of the animal, as it takes flight, for example. Roll neurons preferred upward and downward largefield motion in the ipsilateral and contralateral eyes, respectively, which would result from a roil of the pigeon, head-down to the ipsilateral side.
Yaw neurons preferred forward (nasal to temporal) and backward largefield motion in the ipsilateral and contralateral eyes, respectively, which would result from an horizontal ipsiversive head or body rotation.

Presumably, these binocular receptive fields receive their input from neurons in the $\mathrm{nBOR}$ and LM, most of which have monocular-contralateral receptive fields (Britto et al. 1981; Burns and Wallman 1981; Morgan and Frost 1981; Winterson and Brauth 1985; Wylie and Frost 1990a,b). The nBOR and LM project bilaterally to the IO, which in turn projects to the contralateral VbC (Brecha et al. 1980; Clarke 1977; Freedman et al. 1977). On the basis of the direction selectivity of neurons in the pigeon nBOR (Wylie and Frost 1990a) and LM (Winterson and Brauth 1985; B. J. Frost and B. Morgan, unpublished observations), it is likely that descent cells receive input from up units originating from both $\mathrm{nBOR}$, ascent cells receive projections from down units originating from both $\mathrm{nBOR}$, yaw cells receive input from forward units originating from the contralateral LM and back units originating from the ipsilateral nBOR or LM (see below), and roll cells receive input from up units originating from the contralateral $n B O R$ and down units originating from the ipsilateral $\mathrm{nBOR}$. The direction preferences in response to monocular largefield stimulation of the ipsilateral and contralateral receptive fields of the binocular VbC neurons correspond well to the direction preferences of nBOR ncurons. Wylie and Frost (1990a) found the mean preferred direction of up units in $\mathrm{nBOR}$ was $20^{\circ}$ posterior to the vertical. In the present study the preferred direction in both visual fields of descent cells and the ipsilateral field of roll cells was $10-15^{\circ}$ posterior to vertical. In the nBOR the mean preferred direction of down units was $16^{\circ}$ anterior to the vertical, which corresponds with the preferred direction in both visual fields of ascent cells and the contralateral field of roll cells $\left(10-15^{\circ}\right.$ anterior 
to vertical). Wylie and Frost (1990a) also found that mean preferred direction of back units in the nBOR was $24^{\circ}$ down from the horizontal. Similarly, in the present study, the preferred direction of the contralateral field of yaw cells was $30^{\circ}$ down from the horizontal. Interestingly, the preferred direction for the ipsilateral receptive field of yaw cells was coincident with the visual horizontal. As one would expect, the mean preferred direction of forward units in LM is collinear with the normal visual horizontal (B. J. Frost and B. Morgan, unpublished data), but not collinear with the preferred direction of back units in the nBOR.

\section{Functional organization of the pigeon $\mathrm{VbC}$}

In this study, a clear functional segregation of the CS activity in the $\mathrm{VbC}$ was revealed: cells responding best to translation (ascent and descent) were found in a parasagittal strip medial to a strip containing rotation (roll and yaw) cells. This division was quite sharp, with very little overlap.

In the pigeon cerebellum, five parasagittal zones have been described on the basis of corticonuclear/corticovestibular projections (Arends and Zeigler 1991a) and olivocerebellar connections (Arends and Voogd 1989). These are labeled A, B, C, E, and F from medial to lateral. (Zone D, present in mammals, is not present in the pigeon.) Zone $\mathrm{F}$ includes the auricle and the lateral unfoliated cortex, which is found dorsal to the auricle. On the basis of corticonuclear projections, Arends and Zeigler (1991a) suggest that auricle and lateral unfoliated cortex are homologous to the mammalian flocculus and ventral paraflocculus, respectively. The medial zones A, B, C, and E in ventral IXc,d represent the ventral uvula, and in folium $X$ they comprise the nodulus (Arends and Zeigler 1991a,b). In the present study, rotation cells were found in a sagittal zone in the lateral margin of the $\mathrm{VbC}$, which was adjacent to a medial zone containing translation cells. The division between the two zones was $1.8-2.1 \mathrm{~mm}$ from the midline, which corresponds with the border of the $\mathrm{C}$ and $\mathrm{E}$ zones (Arends and Voogd 1989; Arends and Zeigler 1991a). However, one should note that zone $\mathrm{E}$ is quite narrow $(0.4 \mathrm{~mm})$; thus the rotation-translation division may possibly be between zones $\mathrm{E}$ and $\mathrm{F}$. Together, these data suggest that the flocculus is involved in the processing of rotational flowfields, whereas the nodulus and ventral uvula are specialized for translation flowfields.

\section{Comparison with other species}

Cerebellar neurons responding best to binocular largefield visual motion have been found in species of other vertebrate classes (frogs, Ansorge and Grusser-Cornehls 1977; rat, Blanks and Precht 1983; rabbit, Ghelarducci et al. 1975, Graf et al. 1988, Kano et al. 1990a,b, Kusunoki et al. 1990, Shojaku ct al. 1991; monkey, Waespe and Henn 1981 ). In the rabbit $\mathrm{VbC}$, cells responding best to binocular wholefield stimulation and representing rotational but not translational visual flow have been described. Both yaw cells [dubbed "F/ B cells" by Kano et al. (1990a) and Kusunoki et al. ( 1990) and "vertical axis neurons" by Graf et al. (1988)] and roll cells (U/D cells; Kusunoki et al. 1990; Kano et al. 1990a) have been found in the rabbit VbC. Graf et al. (1988) and later Kano et al. (1990b) showed that roll cells had bipartite receptive fields and are organized with respect to the anterior semicircular canal (see also Shojaku et al. 1991). [In the companion paper (Wylie and Frost 1993 ), we show that this is also the case for the roll cells in the pigeon $\mathrm{VbC}$.] Nevertheless, in the central $90^{\circ}$ of the ipsilateral visual field, upward motion is preferred; and in the central $90^{\circ}$ of the contralateral visual field, downward motion is preferred. Graf et al. (1988) delineated two classes of these neurons based primarily on ocular dominance: "anterior axis neurons" and "posterior axis neurons." Seventy percent of the anterior axis neurons and all posterior axis neurons had binocular receptive fields.

In spite of employing essentially the same methodology for monocular stimulation, Kano et al. (1990a) and Kusunoki et al. (1990) did not report translation cells in the nodulus or flocculus of the rabbit (see also Shojaku et al., 1991). Thus it seems that in the rabbit both the nodulus and flocculus are devoted to rotational flowfield analysis, whereas in the pigeon the nodulus is specialized for translation and the flocculus is specialized for rotation. The only previous report of binocular cerebellar neurons responding to translational wholefield motion is that of Ansorge and Grusser-Cornehls (1977), who described cells in the frog cerebellum that preferred forward motion in both eyes.

There remains the curious absence in the pigeon $\mathrm{VbC}$ of cells responding best to forward and backward translation. Interestingly, most binocular neurons in the nBOR respond best to forward translation (Wylie and Frost 1990b). It should be noted that the most medial 1-mm strip of the ventral uvula and nodulus was not extensively explored in the present study. It is possible that this area contains other classes of translation cells.

\section{Function in the behaving pigeon}

The visual input to the $\mathrm{VbC}$ from the $\mathrm{AOS}$ is involved in the generation of optomotor reflexes to mediate retinal image stabilization (for review see Simpson 1984). One often observes such stabilization in pigeons as they walk. The stereotypical head-bobbing that pigcons display is an optomotor response to the backward visual motion, which occurs as a consequence of forward self-translation (Friedman 1975; Frost 1978). Davies and Green (1988) have also shown that when landing (but not during take-off) pigeons perform head-bobbing behavior (Davies and Green 1988). We presume that the descent neurons are in part responsible for head-bobbing during landing. (Indeed, the predominance of descent neurons over ascent neurons reported here is consistent with the notion that the pigeon $\mathrm{VbC}$ participates in the control of head-bobbing behavior.) During landing, the upward visual flow will induce CS activity of descent neurons, which generate the compensatory upward head movements. Becausc compensatory movements are never complete during the downward translation, the descent neurons will continue to be active during the slow upward compensatory head movement. Thus, even during the slow compensatory movements, the descent neurons are active and continue to generate compensatory movements. It is unknown whether eye movements will also be generated, but perhaps conjugate upward eye movements will occur. 
One can also think of other such straightforward examples that would result in the activation of ascent, roll, and yaw neurons. However, visual flowfields in the environment can be quite complex or inhomogeneous in their structure. For example, during any translational movement, the induced velocity of an object varies with the distance from the point of fixation. At present, we have no information about where the pigeon is fixating, or how depth information reaches the AOS. Differential velocity may not pose a problem for the AOS because, in all species studied, with the exception of rabbits, neurons tend to be broadly tuned for velocity. Another inhomogeneous feature is that some depth planes must be out of focus. However, Soodak and Simpson (1988) have shown that motion sensitivity of neurons in the rabbit AOS are not affected by changes of up to 20 diopters. Complex flowfields could result from self-motion containing both translational and rotational components. For example, if a bird was flying forward and was suddenly "rolled" by a gusting sidewind, the flowfield would contain a roll component superimposed on backward translation. The optimal compensation would require an optomotor response to the roll while disregarding the backward translation, such that the animal would continue forward. How the $\mathrm{VbC}$ roll neurons might execute the appropriate compensation is unclear at this time (for further discussion see Perrone 1992; Perrone and Stone 1991 ). Perhaps the AOS is assisted by neurons in the tectofugal system or telencephalon-neurons that respond to optic flow containing both rotation and translation components. Such neurons have been shown to exist in the cortex of monkeys (e.g., Duffy and Wurtz 1991; Tanaka and Saito 1989).

We thank Drs. R. Benninger, P. Dodwell, K. Grasse, D. Muir, and M. Robertson for comments and valuable discussion.

The research herein was supported by grants to B. J. Frost from the Medical Research Council of Canada (MRC), the Natural Sciences and Engineering Research Council of Canada (NSERC), and the Institute for Robotics and Intelligent Sensors (IRIS). D. R. Wylie was supported by a NSERC postgraduate scholarship.

Present address of D. R. Wylie: Dept. of Physiology and Biophysics, New York University Medical Center, 550 First Ave., New York, NY 10016.

Address reprint requests to $\mathrm{B}$. J. Frost.

Received 24 July 1992; accepted in final form 12 August 1993.

\section{REFERENCES}

ANSORGE, K. AND GRUSSER-CORnehls, U. Visual and visual-vestibular responses of frog cerebellar neurons. Exp. Brain Res. 29: 445-465, 1977.

ARENDS, J. J. A. AND VoOGD, J. Topographical aspects of the olivocerebellar system in the pigeon. Exp. Brain Res. Suppl. 17: 52-57, 1989.

ARENDS, J. J. A. AND ZeIGi.fR, H. P. Organization of the cerebellum in the pigeon (Columba livia). I. Corticonuclear and corticovestibular connections. J. Comp. Neurol. 306: 221-244, 1991 a.

ARENDS, J. J. A. AND ZEIGLER, H. P. Organization of the cerebellum in the pigeon (Columba livia). III. Corticovestibular connections with eye and neck premotor neurons. J. Comp. Neurol. 306: 273-289, 1991b.

BLANKS, R. H. I. AND PRECHT, W. Responses of units in the rat cerebcllar flocculus during optokinetic and vestibular stimulation. Exp. Brain Res. 53: $1-15,1983$

Bodnarenko, S. R. AND MCKenna, O. C. Efferent control of the lentiform nucleus of the mesencephalon in chicken. Soc. Neurosci. Abstr. 13: 864, 1987.
Brecha, N., Karten, H. J., AND Hunt, S. P. Projections of the nucleus of basal optic root in the pigeon: an autoradiographic and horseradish peroxidase study. J. Comp. Neurol. 189: 615-670, 1980.

BritTo, L. G. R., NATAL, C. L., AND MARCONDES, A. M. The accessory optic system in pigeons: receptive field properties of identified neurons. Brain Res. 206: 149-154, 1981.

BuRNS, S. AND WALlman, J. Relation of single unit properties to the oculomotor function of the nucleus of the basal optic root (AOS) in chickens. Exp. Brain Res. 42: 171-180, 1981.

Clarke, P. G. H. The organization of visual processing in the pigeon cerebellum. J. Physiol. Lond. 243: 267-285, 1974.

Clarke, P. G. H. Some visual and other connections to the cerebellum of the pigeon. J. Comp. Neurol. 174: 535-552, 1977.

Correia, M. J., EdEn, A. R., Westlund, K. N., AND Coulter, J. D. A study of some of the ascending and descending vestibular pathways in the pigeon (Columba livia) using anterograde transneural autoradiography. Brain Res. 278: 53-61, 1983.

Davies, M. N. O. AND GREEN, P. R. Head-bobbing during walking, running and flying: relative motion perception in the pigeon. J. Exp. Biol. 138: 71-91, 1988.

DufFy, C. J. AND WuRTz, R. H. Sensitivity of MST neurons to optic flow stimuli. I. A continuum of response selectivity to large-field stimuli. $J$. Neurophysiol. 65: 1329-1345, 1991.

Erichsen, J. T., Hodos, W., Evinger, C., Bessette, B. B., ANd Phillips, S. J. Head orientation in pigeons: postural, locomotor and visual determinants. Brain Behav. Evol. 33: 268-578, 1989.

FreEdMAN, S. L., Voogd J., AND Vielvoye, G. J. Experimental evidence for climbing fibers in the avian cerebellum. I. Comp. Neurol. 175: 243252, 1977.

FRIEDMAN, M. B. Visual control of head movements during avian locomotion. Nature Lond. 225: 67-69, 1975.

Frost, B. J. The optokinetic basis of head-bobbing in the pigeon. J. Exp. Biol. 74: 187-195, 1978.

Frost, B. J., Cavanaugh, P., And Morgan, B. Deep tectal cells in pigeons respond to kinematograms. J. Comp. Physiol. A Sens. Neural Behav. Physiol. 162: 639-647, 1988.

GHElARDUCCI, B., ITO, M., AND YAGI, N. Impulse discharges from flocculus Purkinje cells of alert rabbits during visual stimulation combined with horizontal head rotation. Brain Res. 87: 66-72, 1975.

GiBson, J. J. The Senses Considered as Perceptual Systems. Boston, MA: Houghton Mifflin, 1966.

Gioanni, H., Rey, J., Villalobos, J., AND Dalbera, A. Single unit activity in the nucleus of the basal optic root (nBOR) during optokinetic, vestibular and visuo-vestibular stimulations in the alert pigeon $(\mathrm{CO}$ lumba livia). Exp. Brain Res. 57: 49-60, 1984.

Graf, W., Simpson, J. I., AND LeONARD, C. S. Spatial organization of visual messages of the rabbit's cerebellar flocculus. II. Complex and simple spike responses of Purkinje cells. J. Neurophysiol. 60: 20912121, 1988.

GRASSE, K. L. AND CYNADER, M. S. Electrophysiology of medial terminal nucleus of accessory optic system in the cat. J. Neurophysiol. 51: 276293, 1982.

Gross, N. B. Sensory representation within the cerebellum of the pigeon. Brain Res. 21: 280-283, 1970.

Kano, M., Kano, M.-S., Kusunoki, M., and Maekawa, K. Nature of the optokinetic response and zonal organization of climbing fiber afferents in the vestibulocerebellum of the pigmented rabbit. II. The nodulus. Exp. Brain Res. 80: 238-251, 1990a.

KanO, M.-S., KanO, M., AND MaEKawa, K. Receptive field organization of climbing fiber afferents responding to optokinetic stimulation in the cerebellar nodulus and flocculus of the pigmented rabbit. Exp. Brain Res. 82: 499-512, 1990b.

Karten, H. J. AND Hodos, W. A Stereotaxic Atlas of the Brain of the Pigeon (Columba Livia). Baltimore, MD: Johns Hopkins Press, 1967.

Kusunoki, M., Kano, M., Kano, M.-S., ANd MaEKawa, K. Nature of the optokinetic response and zonal organization of climbing fiber afferents in the vestibulocerebellum to the pigmented rabbit. II. The flocculus. Exp. Brain Res. 80: 225-237, 1990.

LEONARD, C. S., Simpson, J. I., AND GRAF, W. Spatial organization of visual messages of the rabbit's cerebellar flocculus. I. Typology of inferior olive neurons of the dorsal cap of Kooy. J. Neurophysiol. 60: 20732090, 1988.

Maekawa, K., TAKeda, T., AND Kimura, M. Responses of the nucleus of the optic tract neurons projecting to the nucleus reticularis tegmenti 
pontis upon optokinetic stimulation in the rabbit. Neurosci. Res. 2: $1-25,1984$.

MARTIN, G. R. AND Young, S. R. The retinal binocular visual field of the pigeon (Columba livia: English racing homer). Vision Res. 23: $911-$ 915, 1983.

MCKENNA, O. AND WALLMAN, J. Identification of avian brain regions responsive to retinal slip using 2-deoxyglucose. Brain Res. 210: 455460, 1981.

McKenna, O. ANd Wallman, J. Functional postnatal changes in avian brain regions responsive to retinal slip: a 2-deoxy-D-glucose study. $J$. Neurosci. 5: 330-342, 1985.

MIYASHITA, Y. Interaction of visual and canal inputs on the oculomotor system via the cerebellar flocculus. In: Progress in Brain Research. Reflex Control of Posture and Movement, edited by R. Granit and O. Pompeiano. Amsterdam: Elsevier, 1979, vol. 50, p. 695-702.

Morgan, B. AND Frost, B. Visual response properties of neurons in the nucleus of the basal optic root of pigeons. Exp. Brain Res. 42: 184-188, 1981.

NAKAYAMA, K. Differential motion hyperacuity under conditions of common image motion. Vision Res. 21: 1475-1482, 1981.

Nalbach, H.-O., WOlf-Oberhollenzer, F., AND Kirschfeld, K. The pigeon's eye viewed through an ophthalmoscopic microscope: orientation of retinal landmarks and significance of eye movements. Vision Res. 30: 529-540, 1990.

OWEN, B. M. AND LEE, D. N. Establishing a frame of reference. In: Motor Development in Children: Aspects of Coordination and Control, edited by M. G. Wade and H. T. A. Whiting. Dordrecht, Holland: Martinus Nijhoff, 1986.

PERRONE, J. A. A model for the computation of self-motion in biological systems. J. Op. Soc. Am. 9: 177-194, 1992.

Perrone, J. A. AND STONE, L. S. The perception of egomotion: global versus local mechanisms. Inves. Ophthalmol. Visual Sci. Suppl. 32, 1991.

Precht, W., Simpson, J., And Llinas, R. Responses of Purkinje cells in rabbit nodulus and uvula to natural vestibular and visual stimuli. Pfluegers Arch. 367: 1-6, 1976.

SChwarz, D. W. F., AND SCHWARZ, I. E. Projection of afferents from individual vestibular sense organs to the vestibular nuclei in the pigeon. Acta Otolaryngol. 102: 463-473, 1986.

Schwarz, D. W. F., Tomlinson, R. D., And Milne, A. C. Directional specificity for head rotation in pigeons posterior cerebellum. Acta Otolaryngol. 86: 260-268, 1978.

SCHWARZ, I. E. AND SCHWARZ, D. W. F. The primary vestibular projection to the cerebellar cortex in the pigeon (Columba livia). J. Comp. Neurol. 216: 438-444, 1983.

SHOJAKU, H., BARMACK, N. H., AND MizUKOSHI, K. Influence of vestibular and visual climbing fiber signals on Purkinje cell discharge in the cerebellar nodulus of the rabbit. Acta Otolaryngol. 481: 242-246, 1991.

Simpson, J. I. The accessory optic system. Annu. Rev. Neurosci. 7: 13-41, 1984.

Simpson, J. I. AND Alley, K. E. Visual climbing fiber input to rabbit vestibulo-cerebellum: a source of direction-specific information. Brain Res. 82: 302-308, 1974.

Simpson, J. I., Graf, W., AND LeOnard, C. The coordinate system of visual climbing fibers to the flocculus. In: Progress in Oculomotor Research, edited by A. F. Fuchs and W. Becker. Amsterdam: Elsevier, 1981, p. 475-484.

SimpSON, J. I., GRAF, W., AND LEONARD, C. Three-dimensional representation of retinal image movement by climbing fiber activity. Exp. Brain Res. Suppl. 17: 323-337, 1989a.

Simpson, J. I. AND Hess, R. Complex and simple visual messages in the flocculus. In: Control of Gaze by Brain Stem Neurons, edited by R. Baker and A. Berthoz. Amsterdam: Elsevier, 1977, p. 351-360.

Simpson, J. I., LeONARD, C. S., AND SoOdAK, R. E. The accessory optic system of rabbit. II. Spatial organization of direction selectivity. J. Neurophysiol. 60: 2055-2072, 1988.

Simpson, J. I., VAN der Steen, J., TAN, J., Graf, W., and Leonard, C. S. Representations of ocular rotations in the cerebellar flocculus of the rabbit. In: Progress in Brain Research, edited by J. H. J. Allum and M. IIulliger. Amsterdam: Elsevier, 1989b, p. 213-223.

SOODAK, R. E. AND SIMPSON, J. I. The accessory optic system of rabbit. I. Basic visual response properties. J. Neurophysiol. 60: 2037-2054, 1988.

TANAKA, K. AND SAITO, $H$. Analysis of the motion of the visual field by direction, expansion/contraction, and rotation cells clustered in the dorsal part of the medial superior temporal arca of the macaque monkey. J. Neurophysiol. 62: 626-641, 1989.

WAESPE, W. AND HeNN, V. Visual-vestibular interaction in the flocculus of the alert monkey. II. Purkinje cell activity. Exp. Brain Res. 43: 349$360,1981$.

WESTHEIMER, G. AND MCKeE, S. P. Visual acuity in the presence of retinal image motion. J. Opt. Soc. Am. 65: 847-850, 1975.

WhitLOCK, D. G. A neurohistological and neurophysiological study of afferent fiber tracts and receptive areas of the avian cerebellum. $J$. Comp. Neurol. 97: 567-635, 1952.

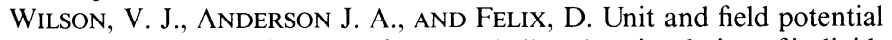
activity evoked in pigeon vestibulocerebellum by stimulation of individual semicircular canals. Exp. Brain Res. 19: 142-157, 1974.

Winterson, B. J. AND BraUth, S. E. Direction-selective single units in the nucleus lentiformis mesencephali of the pigeon (Columba livia). Exp. Brain Res. 60: 215-226, 1985.

WYLIE, D. R. AND Frost, B. J. Visual response properties of neurons in the nucleus of the hasal optic root of the pigeon: a quantitative analysis. Exp. Brain Res. 82: 327-336, 1990a.

WYLIE, D. R. AND FROST, B. J. Binocular neurons in the nucleus of the basal optic root (nBOR) of the pigeon are selective for either translational or rotational visual flow. Visual Neurosci. 5: 489-495, 1990 b.

WyliE, D. R. AND Frost, B. J. Purkinje cells in the vestibulocerebellum of the pigeon respond best to either translational or rotational wholefield visual motion. Exp. Brain Res. 86: 229-232, 1991.

Wylie, D. R. AND Frost, B. J. Responses of pigeon vestibulocerebellar neurons to optokinetic stimulation. II. The 3-dimensional reference frame of rotation neurons in the flocculus. J. Neurophysiol. 70: 26472659, 1993. 